CASE REPORTS

\title{
Periorbital swelling: the important distinction between allergy and infection
}

\author{
P W A Goodyear, A L Firth, D R Strachan, M Dudley
}

Emerg Med J 2004;21:240-242. doi: 10.1136/emj.2002.004051

Orbital cellulitis and abscess formation are rare complications of sinusitis, however acute orbital inflammation is secondary to sinusitis in about $70 \%$ of cases. Delay in diagnosis must not occur to avoid serious complications such as blindness and life threatening intracranial sepsis. A case is reported in which despite late referral, emergency surgical intervention was sight saving.

A 14 year old boy presented to the accident and emergency department of a district general hospital with a 24 hour history of a painful swollen left eye, exacerbated by movement. A history of allergy to dog hair was noted. On examination there was unilateral periorbital swelling of the left eye with a normal conjunctiva (fig 1). An allergic reaction was diagnosed and treated with piriton and sodium chromoglycate eye drops.

Two days later at review he was systemically unwell and had a temperature of $39.3^{\circ} \mathrm{C}$. The left sided periorbital swelling had worsened. Visual acuity and fluorescein staining were unremarkable. He was noted to have bilateral large erythematous tonsils. It was felt at that time to be a worsening allergic reaction. However, oral flucloxacillin was added, and ophthalmology review was arranged for the following day.

Ophthalmology assessment four days after the onset of symptoms revealed the salient features of a recent upper respiratory tract infection and a long history of a blocked left nostril and snoring.

On examination there was proptosis, swollen and erythematous eyelids, chemosis of the sclera, and restricted eye movements. There was pronounced left maxillary tenderness.

Blood tests revealed white cells of $18 \times 10^{9} / 1$ with a neutrophilia and C reactive protein of 128 . Urgent computed tomography demonstrated left proptosis with considerable soft tissue swelling (fig 2). All sinuses on the left were filled with fluid. There was enhancing inflammatory tissue in the inferior aspect of the orbital floor, with associated gas. The optic nerve and orbital soft tissue were enlarged. The diagnosis of left orbital cellulitis secondary to maxillary sinusitis was made and the patient was admitted under the care of ENT and ophthalmologists.

The patient underwent emergency endoscopic drainage of left orbital abscess, endoscopic sinus surgery, and subcutaneous abscess aspiration resulting in a noticeable reduction in proptosis. Maximum dose intravenous cefuroxime and metronidazole were started. Microscopy and culture revealed Streptococcus millieri. Though showing steady improvement after surgery, the patient returned to theatre two days later for aspiration of the subcutaneous cheek abscess and repeat antral wash out. He was discharged home three days later and was well at his six week outpatient follow up appointment.

\section{DISCUSSION}

Orbital cellulitis is an emergency. It is important that it is recognised early and managed aggressively. Although the incidence of orbital cellulitis has remained low with better primary health care and availability of a broad range of antibiotics, it is often a difficult problem to manage and may cause blindness if left untreated because of optic nerve compression. Both orbital abscess and cavernous venous thrombosis may lead to intracranial spread of infection, such as meningitis or cerebral abscess with high morbidity and possible mortality.

The serious risk of complications in such cases was made clear by Hodges et al ${ }^{1}$ who studied the outcome in orbital cellulitis in a developing country. They found a high rate of complications, $52 \%$ blind on admission, with no improvement after treatment and a mortality of $4 \%$ because of cavernous venous thrombosis. These results reflected the delay in presentation in this population.

Box 1 illustrates the differential diagnosis of periorbital swelling.

The orbital septum is a thin membrane that originates from the orbital periosteum and inserts into the anterior surfaces of the tarsal plates of the eyelids. The septum separates the superficial eyelid from the deeper orbital structures, and it forms a barrier that prevents infection in the eyelid from extending into the orbit. Preseptal cellulitis differs from orbital cellulitis in that it is confined to the soft tissues that are anterior to the orbital septum.

Orbital allergic reaction includes, conjunctival injection, blepharitis, periorbital dermatitis, and oedema of the eyelid. ${ }^{2}$ Pruritis and oedema are the most common clinical findings, although this is usually bilateral.

Table 1 shows the main differences in presentation between cellulitis and eye allergy.

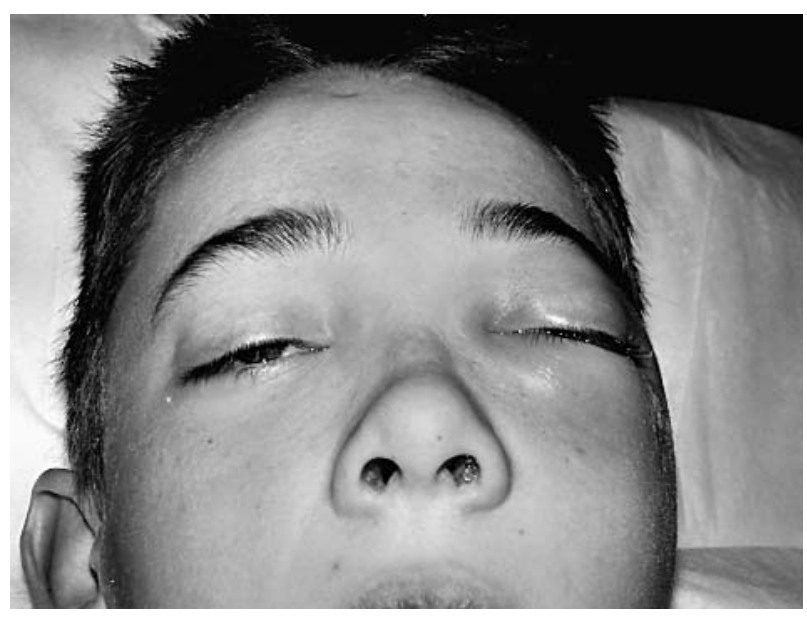

Figure 1 Left sided periorbital swelling and proptosis. 


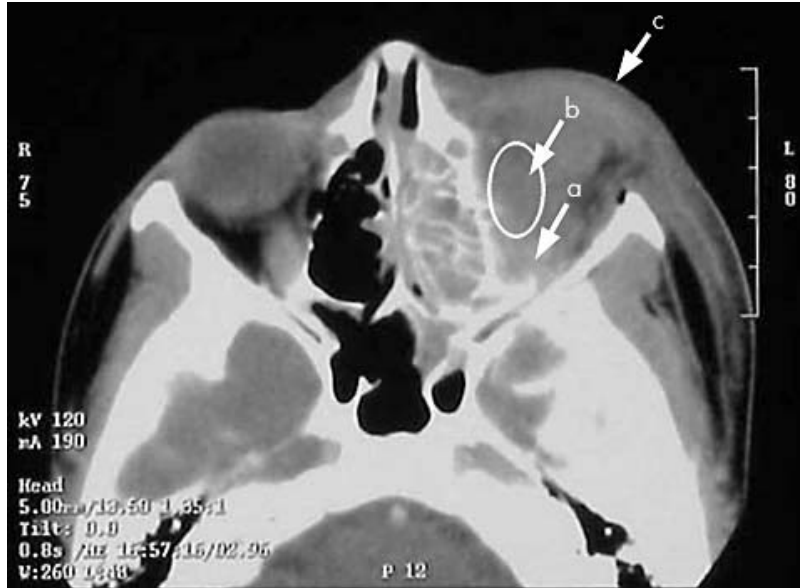

Figure 2 CT scan showing the orbit with the optic nerve (a), compressed by the orbital abscess (b). Proptosis and soft tissue swelling (c) is also shown.

Table 1 Difference in presentation

\begin{tabular}{ll}
\hline Infective & Allergy \\
\hline Subacute & Acute \\
Pyrexial & Apyrexial \\
Unilateral & Bilateral \\
Eyelid oedema and erythema & Eyelid oedema and erythema \\
Conjunctivitis & Pruritis and conjunctivitis \\
Chemosis & Blepharitis \\
Painful restricted eye movements & Normal eye movements \\
Altered visual acuity & Normal visual acuity \\
Relative afferent papillary defect & Normal pupils \\
Proptosis & History of topical \\
& medication/allergen \\
Meningism & \\
Possible other cranial nerve palsy & \\
\hline
\end{tabular}

Within the accident and emergency or general practice setting it is important to recognise an infected eye that requires urgent specialist referral.

The distinction between preseptal cellulitis and orbital cellulitis is important, but this is often difficult clinically and can be made by the appropriate specialist who has access to investigations such as CT scans.

Sinusitis is the most common predisposing factor to orbital cellulitis and abscess formation. Figures of $60 \%-91 \%$ of orbital cellulitis secondary to sinusitis have been reported. ${ }^{13-6}$ Ethmoidal and maxillary sinuses are most commonly affected. ${ }^{3478}$ Bacterial orbital cellulitis attributable to sinusitis is primarily a disease of the paediatric population, ${ }^{34}$ although it can affect any age group. Ferguson et al found that $91 \%$ of the paediatric population with orbital cellulitis

\section{Box 1 Differential diagnosis}

- Preseptal cellulitis

- Orbital cellulitis/abscess

- Dacryocystitis

- Trauma

- Allergic eye

- Uveitis

- Neoplasm

- Eyelid insect bite

\section{Box 2 Important lessons}

- Unilateral swelling of the orbit is more likely to be infection than allergy

- Early referral from primary care or A\&E is essential to avoid serious complications

- Close cooperation between paediatrics, ophthalmology, and ENT is vital to ensure optimum patient management

had sinusitis, with $38 \%$ having multiple sinus involvement. Some studies report a peak incidence between 6-15 year olds, ${ }^{4}$ while others report a bimodal distribution, with another peak in incidence at $60-70$ years. There is also a male preponderance to the condition, ${ }^{14589}$ although no satisfactory explanation can be offered for this observation. A seasonal variation ${ }^{4}$ is attributable to the increased incidence of upper respiratory tract infection at these times of the year.

Administration of oral antibiotics may change the presentation, which may be relevant if the patient has already seen their general practitioner or been admitted to a paediatric/other ward. It is not uncommon for children to be admitted to a paediatric ward with an orbital infection. Hereafter there may be a delay in further investigations and specialist referral, as the urgency of the condition may not be fully appreciated.

It is well reported that CT is the investigation of choice ${ }^{3-10}$ for orbital cellulitis, permitting accurate localisation of the sinus infection and grading of the orbital inflammation. Studies have shown that $30 \%$ of patients with suspected preseptal cellulitis have evidence of orbital involvement on CT scan. ${ }^{6}$

General management principles should include (1) obtaining adequate specimens for microbiological studies; (2) high dose broad range of intravenous antibiotics; (3) changing antibiotics according to sensitivities; and (4) intervening surgically at the appropriate time. This is usually after 24 hours, if there is no response to medical management. The authors could find no agreed antibiotic regimen in the literature. Principles of surgical management include (1) temporary orbital decompression; (2) drainage of orbital or subperiosteal abscess, via external or endoscopic routes; and (3) drainage of effected sinuses.

There were no long term complications in this particular case, but it does highlight that orbital inflammation should not be immediately blamed on allergy. It needs sufficient evaluation to exclude cellulitis or abscess formation, even without clinically obvious sinusitis.

Orbital cellulitis usually presents to the general practitioner, paediatrician, or accident and emergency department. Rarely do the ENT surgeons or ophthalmologists see it initially. Multiple abnormalities may be present, so close cooperation between all these specialties is vital for the successful management of this condition.

The authors believe that all patients with orbital inflammation require hospitalisation and CT scan without delay. We agree with Tole et $a l^{6}$ who concluded that "A high index of suspicion and a low threshold for early specialist referral is required for optimal management of orbital cellulits".

\section{Authors' affiliations}

P W A Goodyear, A L Firth, D R Strachan, Department of

Otolaryngology, Bradford Royal Infirmary, Bradford, UK

M Dudley, Department of Accident and Emergency, Airedale General Hospital, Steeton, West Yorkshire, UK 
Correspondence to: MrD R Strachan, Department of Otolaryngology, Bradford Royal Infirmary, Duckworth Lane, Bradford BD9 6RJ, UK; drstrachan@aol.com

Accepted for publication 11 March 2003

\section{REFERENCES}

1 Hodges E, Tabbara KF. Orbital cellulitis: review of 23 cases from Saudi Arabia. Br J Ophthalmol 1989;73:205-8.

2 Bielory L. Allergic and immunologic disorders of the eye. Part II: ocular allergy. J Allergy Clin Immunol 2000;106:1019-32.

3 Davis JP, Stearns MP. Orbital complications of sinusitis: avoid delays in diagnosis. Postgrad Med J 1994;70:108-10.
4 Ferguson MP, McNab AA. Current treatment and outcome in orbital cellulitis. Aust N Z J Ophthalmol 1999;27:375-9.

5 Seah LL, Fu ERY. Acute orbital cellulitis - a review of 17 cases. Ann Acad Med Singapore 1997; 26:409-14.

6 Tole DM, Anderton LC, Hayward JM. Orbital cellulitis demands early recognition, urgent admission and aggressive management. J Accid Emerg Med 1995; 12:151-3.

7 El-Silimy O. The place of endonasal endoscopy in the treatment of orbital cellulitis. Rhinology 1995;33:244-5.

8 Eufinger $\mathrm{H}$, Machtens $\mathrm{E}$. Purulent pansinusitis, orbital cellulitis and rhinogenic intracranial complications. J Craniomaxillofac Surg 2001;29:111-17.

9 Moloney JRM, Badhan NJ, McRae A. The acute orbit: preseptal (periorbital) cellulitis, subperiosteal abscess and orbital cellulitis due to sinusitis. J Laryngol Otol 1987:12:1-18.

10 Starkey CR, Steele RW. Medical management of orbital cellulitis. Pediatr Infect Dis J 2001;20:1002-5.

\section{Ludwig's angina}

\section{K Saifeldeen, R Evans}

The case is described of an occurrence of Ludwig's angina with advanced stage of the disease with progressive and rapid airway compromise and fatal consequence. A review of the literature is undertaken to gain a better understanding of the disease, and gives the opportunity for presenting a summary of the key issues regarding this dreaded disease, particularly the immediate management of it in the emergency department.

A previously healthy 40 year old man presented to our accident and emergency department with difficulty breathing. He had been taking antibiotics for a week for a sore throat that had developed after dental extraction. His symptoms had worsened with rapidly increasing shortness of breath during the past 24 hours. On arrival to our department, he had noisy (gurgling) breathing with drooling saliva, dyspnoea, dysphagia, and trismus. There was bilateral submandibular tense swellings and cellulitis, larger on the left. He was not able to protrude his tongue, which appeared elevated. He was feverish $\left(39.2^{\circ} \mathrm{C}\right)$ and had a pulse rate of $130 / \mathrm{min}$. His blood pressure was $180 / 94$ and a respiratory rate of $25 / \mathrm{min}$. His oxygen saturation was $95 \%$ on air and $99 \%$ on $15 \mathrm{l} / \mathrm{min}$ oxygen. Our immediate management of the patient included maintaining his upright sitting posture with continuous high oxygen flow administration.

The anaesthetic and ENT teams were involved immediately. He was given $6 \mathrm{mg}$ of intravenous dexamethasone, $1.2 \mathrm{~g}$ of augmentin, intravenous hydration, and nebulised adrenalin. Twenty minutes from arrival, the patient's clinical picture had not changed. As he appeared stable, a decision was made for the immediate transfer of the patient to the operating theatre for an emergency tracheostomy under local anaesthetic followed by drainage of the submandibular swellings under general anaesthetic. In the operating room and before transferring the patient onto the operating table he developed an acute complete airway obstruction and respiratory arrest. An immediate tracheostomy and intubation performed. Asystole cardiac arrest followed. The patient was successfully resuscitated five minutes after arrest. The floor of the mouth was then drained. The patient was transferred to the intensive care unit. He unfortunately developed hypoxic ischaemic encephalopathy with failure to gain consciousness, decerebrate extensor spasms of the upper and lower limbs, and recurrent epileptic fits. He was eventually weaned off the ventilator and started breathing spontaneously. The neck swelling subsided and the drain was removed. He was then transferred to the neurological rehabilitation ward. He died of bilateral lower lobe bronchopneumonia, three weeks after his admission.

\section{COMMENT}

Ludwig's angina is best described by Karl Friedrich Wilhelm von Ludwig in 1836, as a rapidly and frequently fatal progressive gangrenous cellulitis and oedema of the soft tissues of the neck and floor of the mouth. It originates in the region of the submandibular gland with elevation and displacement of the tongue. The disease extends by continuity rather than lymphatic spread. Airway compromise has been recognised as the leading cause of death. Mortality exceeded 50\%, but since the introduction of antibiotics in 1940s, improved oral and dental hygene, and aggressive surgical approach the mortality was reduced significantly. This resulted in the rare occurrence of the disease leaving many physicians with increasingly limited experience of Ludwig's angina.

Most Ludwig's angina infections are odontogenic. ${ }^{1}$ Other causes include peritonsillar or parapharyngeal abscesses, mandibullar fracture, oral lacerations/piercing, or submandibullar sialodentitis. Predisposing factors include: dental carries, recent dental treatment, systemic illnesses such as diabetes mellitus, malnutrition, alcoholism, compromised immune system such as AIDS, and organ transplantation and trauma. $^{2-5}$ In children, it can occur de novo, without any apparent cause. ${ }^{67}$ Early recognition of the disease is of paramount importance. Painful neck swelling, tooth pain, dysphagia, dyspnoea, fever, and malaise are the most common complaints. Neck swelling and a protruding or elevated tongue are seen in the vast majority. Stridor, trismus, cyanosis, and tongue displacement suggest an impending airway crisis. Oedema and induration of the anterior neck, often with cellulitis, may be present in advanced cases. Early signs and symptoms of obstruction may be subtle.

Airway compromise is always synonymous with the term Ludwig's angina, and it is the leading cause of death. Therefore, airway management is the primary therapeutic 
concern. ${ }^{8}$ The treatment plan for each patient should be individualised and based on a number of factors. The stage of the disease and comorbid conditions at the time of presentation, physician experience, available resources, and personnel are all crucial factors in the decision making. ${ }^{9}$ Immediate involvement of the anaesthetic and otolaryngology team is crucial. If surgical procedure is necessary, then airway control becomes mandatory. Airway observation policy is appropriate in selected cases of lesser severity. It entails aggressive medical treatment and close observation, monitoring, and regular examination. ${ }^{10}$ Flexible nasotracheal intubation requires skills and experience, if it is not feasible, cricothyrotomy and tracheostomy under local anaesthetic may be required, and this is occasionally performed in the emergency department in those with advanced stage of the disease. Tracheostomy and cricothyrotomy can in such cases be associated with difficulties and complications. ${ }^{11}$ Endotracheal intubation is associated with high rate of failure with acute deterioration in respiratory status resulting in emergency "slash" tracheostomy. Elective awake tracheostomy is a safer and more logical method of airway management in patients with a fully developed Ludwig's angina. ${ }^{12}$

Observations from previous case studies have suggested that the use of intravenous dexamethazone and nebulised adrenaline often allow intubation to be carried out under more controlled conditions, often avoiding the need for tracheostomy or criccothyroidotomy. An initial dose of $10 \mathrm{mg}$ of dexamethasone is followed by $4 \mathrm{mg}$ every six hours for 48 hours. The dexamethasone reduces oedema and cellulitis, it provides the initial chemical decompression protecting the airway and allows improved antibiotic penetration into the area. ${ }^{13}{ }^{14}$ Nebulised adrenaline $(1 \mathrm{ml}$ of 1:1000 diluted to $5 \mathrm{ml}$ of $0.9 \%$ saline) is believed to be safe and effective in reducing upper airway obstruction of differing aetiologies. ${ }^{15}$ Causative bacteria are usually a mix of aerobes and anaerobes, including mouth organisms such as streptococci or staphylococci. ${ }^{7812}$ High doses of penicillin G, with metronidazole or clindamycin or co-amoxiclav, are all good initial agents. Aerobic Gram negative organisms are uncommon in deep neck abscesses and the use of gentamicin is not recommended in the initial management. ${ }^{12}$ The patient must be maintained in a sitting posture, and should never be left unattended. Other complications such as descending necrotising mediastinitis usually occur through the retropharyngeal space $(71 \%)$ and the carotid sheath $(21 \%) .{ }^{16}$ The use of contrast enhanced computed tomography is not essential to confirm the diagnosis of Ludwig's angina but it is used to assess the extent of the abscess in all cases of retropharyngeal extension. $^{12}$

In conclusion, Ludwig's angina is a potentially lethal disease. We believe that many accident and emergency departments have limited experience with the disease because of its rare occurrence. Management must entail early diagnosis and the immediate aggressive medical approach by the emergency, anaesthetic, and otolaryngology teams, with securing and maintaining the airway being the primary goal in all patients presenting with Ludwig's angina.

\section{Contributors}

$\mathrm{K}$ Saifeldeen was involved in management of the patient in the accident and emergency department, carried out the literature search, and wrote the paper. R Evans was the consultant ENT surgeon responsible for the care of the patient and contributed to the writing of the paper.

\section{Authors' affiliations}

K Saifeldeen, Accident and Emergency Department, Princes of Wales Hospital, Bridgend, UK

R Evans, ENT Department, Princess of Wales Hospital

Correspondence to: Dr K Saifeldeen, Accident and Emergency Department, Princes of Wales Hospital, Coity Road, Bridgend, CF31 1RQ, UK; knsaifeldeen@btinternet.com

Accepted for publication 30 October 2003

\section{REFERENCES}

1 Quinn FB. Ludwig's angina. Arch Otolaryngol Head Neck Surg 1999; 125:599.

2 Owens BM, Schuman NJ. Ludwig's angina. Gen Dent 1994;42:84-7.

3 Owens BM, Schuman NJ. Ludwig's angina: historical perspective. J Tenn Dent Assoc 1993;73:19-21.

4 LeJeune HB, Amedee RG. A review of odontogenic infections. J La State Med Soc 1994; 146:239-41.

5 Finch RG, Snider GE, Sprinkle PM. Ludwig's angina. JAMA 1980;243:1171-3.

6 Kurien M, Mathew J, Job A, et al. Ludwig's angina. Clin Otolaryngol 1997;22:263-5.

7 Har-EL G, Aroesty JM, Shaha A, et al. Changing trends in deep neck abscesses. Oral Surg Oral Med Oral Pathol 1994;77:446-50.

8 Moreland LW, Corey J, McKenzie R. Ludwig's angina: report of a case and review of the literature. Arch Intern Med 1988;148:461-1.

9 Shockley WW. Ludwig's angina-a review of current airway management. Arch Otolaryngol Head Neck Surg 1999;125:600.

10 Bradley F, Marlpe. Ludwig's angina. Review of current airway management. Arch Otolaryngol Head Neck Surg 1999; 125:596-9.

11 Neff S PW, Mery AF, Anderson B. Airway management in Ludwig's angina. Anaesth Intensive Care 1999;27:659-61.

12 Parhiscar A, Har-El G. Deep neck abscess: a retrospective review of 210 cases. Ann Otol Rhinol Laryngol 2001;110:1051-4.

13 Bush RF, Shaha D. Ludwig's angina- improved treatment. Otolaryngol Head Neck Surg 1997;117:S172-5.

14 Freud B, Timon C. Ludwig's angina: a place for steroid therapy in its management. Oral Health 1992;82:23-5.

15 MacDonnell SPJ, Timmins AC, Watson JD. Adrenalin administred via a nebuliser in adult patients with upper airway obstruction. Anaesthesia 1995;50:35-6.

16 Furst IM, Ersil P, Caminiti M. A rare complication of tooth abscess-Ludwig's angina and mediastinitis. J Can Dent Assoc 2001;67:324-7. 


\title{
Endocarditis diagnosed as multilobar, community acquired pneumonia
}

\author{
C D Muntan, M Haydel
}

Emerg Med J 2004;21:244-245. doi: 10.1136/emj.2002.004721

W ith the introduction of penicillin in the 1940s, the mortality rate from infective endocarditis (IE) decreased from $100 \%$ to about $30 \% .{ }^{1}$ Despite newer antibiotics and other medical advances, the mortality rate remains $16 \%$ to $46 \%$, and the annual incidence for the general population is 24 to 62 cases per million. ${ }^{2-11}$

Infective endocarditis has changed over the decades from a disease infecting rheumatic heart defects to an iatrogenic and self inflicted entity. With advances in invasive medical techniques and an increase in intravenous drug use, the prevalence of staphylococcus aureus has now surpassed streptococcus as the most common cause of IE. $^{11-13}$ In addition, there is an increasing prevalence of resistant bacteria, poor compliance with treatment regimens, and risk of complications years later. ${ }^{8-10} 14$

The initial presentation to the emergency department (ED) is usually vague and non-specific, especially among intravenous drug users, and the number of missed diagnoses is unknown. ${ }^{15}$ The following case illustrates IE and its presentation and management.

A 23 year old woman presented to the ED complaining of lower extremity pain and swelling for five days. The patient was seen at an outlying ED six days previously, with a three week history of subjective fever and cough. She was diagnosed with multilobar, community acquired pneumonia and was prescribed levofloxacin. The fever continued; she developed bilateral knee and ankle pain, and a rust coloured sputum. The patient denied rashes, insect bites, chest pain, or vaginal discharge. Her medical history was negative for sexually transmitted diseases, heart murmurs, rheumatic fever, intravenous drug use, or recent dental work.

On physical examination, her pulse was 144 beat/min, blood pressure 109/46, respirations 28 breath/min, temperature $39.4^{\circ} \mathrm{C}$, pulse oximetry $99 \%$ on room air. She had a normal mental status. Her mucous membranes were dry and her jugular veins were flat. She had no cardiac murmurs or gallops. She had bibasilar crackles and decreased breath sounds bilaterally although was not in respiratory distress. Her right third metacarpophalageal joint was swollen and tender, and she had mild bilateral swelling of the ankles without erythema, warmth, or tenderness. She had no rashes, peripheral oedema, Osler's nodes, splinter haemorrhages, Janeway lesions, or Roth's spots.

ED management included normal saline bolus for suspected dehydration, acetaminophen, laboratory investigations, and chest radiograph. After two litres of intravenous fluids, repeat vital signs were: pulse 102 beat $/ \mathrm{min}$, blood pressure 100/52, respirations 28 breath/min, temperature $37.7^{\circ} \mathrm{C}$. A repeat cardiac examination revealed a II/VI systolic murmur at the left lower sternal border. Her chest radiograph showed focal confluence of opacities peripherally in the middle lung zones and lung bases that were consistent with infection or septic emboli. Her white blood cell count was 16.5 with 67 segs, 16 bands, 10 lymphocytes, and 7 monocytes. Her urine pregnancy test and urine analysis were

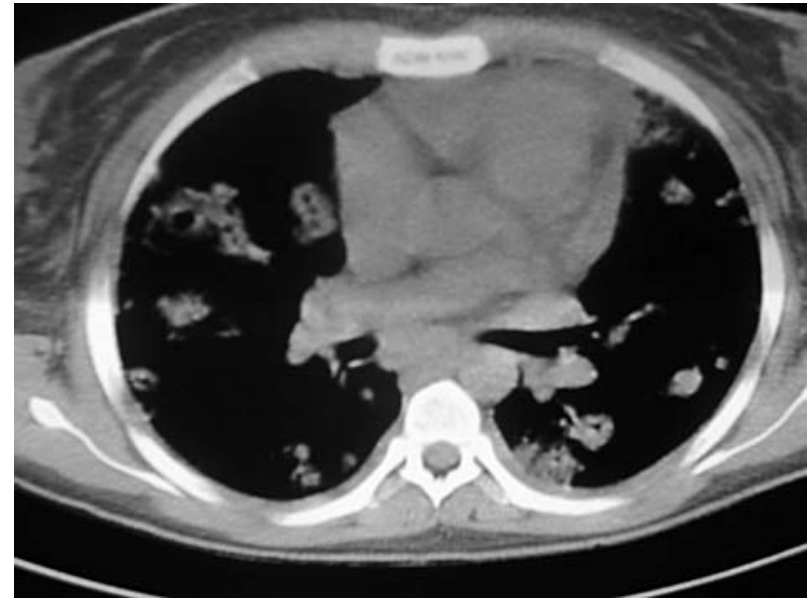

Figure 1 Computed tomography of chest.

negative. Her electrolyte panel was normal but sedimentation rate was 95 .

The patient was prescribed immediately intravenous nafcillin and gentamicin. While in the ED, a transthoracic echocardiogram and computed tomography of the chest were ordered, and the internal medicine team was consulted. Computed tomography showed innumerable peripheral opacities, many of which displayed central cavitations; consistent with septic emboli (fig 1). The transthoracic echo showed large mobile masses on the tricuspid valve. Under the modified Duke criteria, the patient's new murmur and echocardiogram results met two major criteria, categorising the diagnosis as "definite" infective endocarditis. ${ }^{76} 17$

Once admitted, a transoesophageal echocardiogram showed vegetations on all tricuspid leaflets, severe tricuspid regurgitation, and evidence of early right sided dilatation. Blood cultures from all four bottles grew staphylococcus aureus, sensitive to oxacillin (MSSA). The cardiothoracic surgical team evaluated the patient and recommended valve replacement surgery. The patient refused surgery and was discharged home after completing a six week course of intravenous antibiotics.

\section{DISCUSSION}

Since the publication of the Duke criteria in 1994, many studies have validated the sensitivity, emphasised the use of echocardiography, and offered suggestions for modification of the criteria. ${ }^{11}{ }^{17-19}$ The modified Duke criteria now include three major (new murmur, positive blood cultures, vegetations found on echocardiogram) and six minor (predisposition, fever, vascular phenomena, immunological phenomena, microbiological findings, other echocardiographic evidence) criteria. To date, no studies have validated whether this improved criteria has decreased the mortality rate. In 
addition, there are no studies in the ED literature that quantify the misdiagnosis of IE. Many other studies have shown that the transthoracic approach is much easier to perform but inadequate in up to $20 \%$ of adult patients because of body habitus, chronic obstructive pulmonary disease, or chest wall deformities. Because of increased sensitivity, transoesophageal echocardiogram is recommended as the test of choice. ${ }^{11} 20-22$

In conclusion, emergency physicians must recognise the unchanged mortality rate with IE and understand the importance of early, reliable diagnosis. The most common initial presentation to the ED for endocarditis is intermittent fever and malaise. ${ }^{22}$ Likewise, $15 \%-20 \%$ of left sided infected patients and $50 \%-65 \%$ of right sided infected patients will not have a murmur on initial examination. ${ }^{22}{ }^{23}$ This emphasises the importance of searching for risk factors in the history, looking for other physical examination findings, understanding the modified Duke criteria, and using transoesophageal echocardiograms. Emergency physicians must always include IE in the differential diagnosis for unexplained or persistent febrile illness.

\section{Authors' affiliations \\ C D Muntan, M Haydel, Section of Emergency Medicine, LSU-Charity} Hospital, New Orleans, USA

Correspondence to: Dr C D Muntan, Section of Emergency Medicine, LSU-Charity Hospital, 1532 Tulane Avenue, 13th Floor, New Orleans, LA, USA; cmunta@luhsc.edu

Accepted for publication 18 February 2003

\section{REFERENCES}

1 Durack D. Infective endocarditis. Infect Dis Clin North Am 2002;16:15.

2 Hoen B, Alla F, Selton-Suty C, et al. Changing profile of infective endocarditis: results of a 1-year study in France. JAMA 2002;288:75-81.

3 Wallace SM, Walton BI, Kharbanda RK, et al. Mortality from infective endocarditis: clinical predictors of outcome. Heart 2002;88:53-60.
4 Tak T, Reed KD, Haselby RC, et al. An update on the epidemiology, pathogenesis and management of infective endocarditis with emphasis on Staphylococcus aureus. Wis Med J 2002;101:24-33.

5 Delahaye F, Goulet V, Lacassin F, et al. Characteristics of infective endocarditis in France in 1991. A 1-year survey. Eur Heart $J$ 1995; 16:394-401

6 Hogevik H, Olaison L, Andersson R, et al. Epidemiologic aspects of infective endocarditis in an urban population. A 5-year prospective study. Medicine 1995:74:324-39.

7 Mandell GL, Bennett JE, Dolin R. Mandell: principles and practice of infectious diseases. 5th edn. Edinburgh: Churchill Livingstone, 2000:857.

8 Mylotte JM, McDermott C, Spooner JA. Prospective study of 114 consecutive episodes of Staphylococcus aureus bacteremia. Rev Infect Dis 1987:9:891-907.

9 Roder BL, Wandall DA, Frimodt-Moller N, et al. Clinical features of Staphylococcus aureus endocarditis: a 10-year experience in Denmark. Arch Intern Med 1999; 159:462-9.

10 Watanakunakorn C. Staphylococcus aureus endocarditis at a community teaching hospital, 1980 to 1991. An analysis of 106 cases. Arch Intern Med 1994; 154:2330-5.

11 Bouza E, Menasalvas A, Munoz P, et al. Infective endocarditis-a prospective study at the end of the twentieth century: new predisposing conditions, new etiologic agents, and still a high mortality. Medicine 2001;80:298-307.

12 Cabell $\mathrm{CH}$, Jollis JG, Peterson GE, et al. Changing patient characteristics and the effect on mortality in endocarditis. Arch Intern Med 2002;162:90-4.

13 Mylonakis E, Calderwood SB. Infective endocarditis in adults. N Engl J Med 2001;345:1318-30.

14 Hoen B. Special issues in the management of infective endocarditis caused by Gram-positive cocci. Infect Dis Clin North Am 2002;16:437-52.

15 Roberts R, Slovis CM. Endocarditis in intravenous drug abusers. Emerg Med Clin North Am 1990;8:665-81.

16 Durack DT, Lukes AS, Bright DK. New criteria for diagnosis of infective endocarditis: utilization of specific echocardiographic findings. Am J Med 1994;96:200-9.

17 Bayer AS, Bolger AF, Taubert KA, et al. Diagnosis and management of infective endocarditis and its complications. Circulation 1998:98:2936-48.

18 Palepu A, Cheung SS, Montessori V, et al. Factors other than the Duke criteria associated with infective endocarditis among injection drug users. Clin Invest Med 2002;25:118-125.

19 Li JS, Sexton DJ, Mick N, et al. Proposed modifications to the Duke criteria for the diagnosis of infective endocarditis. Clin Infect Dis 2000:30:633-8.

20 Shively BK, Gurule FT, Roldan CA, et al. Diagnostic value of transesophageal compared with transthoracic echocardiography in infective endocarditis. JAm Coll Cardiol 1991; 18:391-7.

21 Thalme A, Nygren AT, Julander I, et al. Endocarditis: clinical outcome and benefit of transoesophageal echocardiography. Scand J Infect Dis 2000;32:303-7.

22 Marx JA, ed. Rosen's emergency medicine: concepts and clinical practice. 5th edn. St Louis: Mosby, 2002:1150.

23 Tintinalli JE, Kelen GD, Stapczynski JS, eds. Emergency medicine: a comprehensive study guide. 5th edn. New York: McGraw-Hill, 2000:385.

\section{Distinguishing dural sinus thrombosis from benign intracranial hypertension}

\section{S Khandelwal, C D Miller}

Dural sinus thrombosis (DST) is a life threatening illness and is often overlooked but it must be considered in the differential diagnosis of a patient presenting with a significant headache. DST presents similarly to benign intracranial hypertension $(\mathrm{BIH})$ with intracranial hypertension and headache. A case of a 23 year old woman with DST is described that was initially diagnosed as $\mathrm{BIH}$. A Medline search to determine the examination of a patient with suspected BIH or DST yielded several articles on this topic but only two brief case reports in the emergency medicine literature. Any patient with suspected DST or BIH must have a confirmatory magnetic resonance imaging and magnetic resonance venography study. Treatment of DST seems to be effective, considerably different from BIH, and lack of treatment may lead to increased morbidity and mortality.
$T$ he evaluation of a patient with a severe or unusual headache in the emergency department (ED) is not limited to the "don't miss" diagnoses of subarachnoid haemorrhage, meningitis, intracranial mass, or intracranial haemorrhage. Other entities that need to be considered are the range of diseases that may cause raised intracranial pressure such as dural sinus thrombosis (DST) and benign intracranial hypertension (BIH). The typical evaluation for a severe headache in the ED often includes head computed tomography (CT) as well as lumbar puncture. With a normal CT and a lumbar puncture showing raised intracranial

Abbreviations: DST, dural sinus thrombosis; $\mathrm{BH}$, benign intracranial hypertension; SSS, superior sagital sinus; CT, computed tomography; $\mathrm{MRI}$, magnetic resonance imaging; MRV, magnetic resonance venography 
pressure the examination may end with the resultant diagnosis being BIH. It is very important to understand that $\mathrm{BIH}$ is a diagnosis of exclusion and must be distinguished from other causes of intracranial hypertension such as DST. Failure to timely diagnose DST or misdiagnosis as BIH can lead to significant morbidity and mortality as treatment with heparin and oral anticoagulants seems to significantly improve outcome.

\section{CASE REPORT}

A 23 year old moderately obese white woman with a recent diagnosis of BIH three days previously presented to another rural ED with worsening headaches, confusion, and new onset seizure. On arrival to that ED she was noted to be febrile, slightly disoriented, but able to follow commands. Diagnostic testing at that facility included a head CT, interpreted as negative by that institution's radiologist. Therapeutic interventions included the administration of ceftriaxone and acyclovir. The treating physician wanted to perform a lumbar puncture but the family refused and requested transfer to our facility stating they wanted "the experts". The patient was transferred to our facility, a tertiary care referral centre, via aeromedical transport with a suspected diagnosis of worsening BIH versus meningitis. The time from presentation to the transferring facility to arrival in our emergency department was less than three hours. The patient arrived at our hospital unable to provide any additional history because of her decreased mentation. Family members gave some insight into the patient's recent history. The patient three days previously had visited an emergency department with complaints of headache. At that visit she was diagnosed with BIH based on the results of a negative head CT, and a lumbar puncture showing raised intracranial pressure; a magnetic resonance imaging (MRI) study was not performed or scheduled for in the near future. An outpatient neurology appointment was to be made by the patient. The family stated that the patient had been having increased headache over the past two days as well as subjective fevers. She was an otherwise healthy young woman, the only drug she was taking was oral contraceptives, and her social history was noticeable only for being a smoker of one pack a day.

Examination on arrival in our emergency department revealed a lethargic woman, a definite change from the report given to the accepting physician before transfer. The patient did not follow any commands, opened eyes to physical stimulation, localised to pain, and spontaneously moved all extremities. Secondary to concerns that the patient was suffering from a significant neurological insult, as well as concerns for airway protection, a decision was made to undergo rapid sequence intubation and provide mechanical ventilation. A repeat non-contrast head CT was immediately performed showing thrombosis in the superior sagital sinus (SSS), both transverse sinuses (fig 1), and straight sinus. There was also diffuse cerebral swelling. Both our neuroradiologists and neurosurgeons felt the head CT was consistent with a diagnosis of DST. A review of a copy of the CT scan performed at the transferring facility brought by the aeromedical transport team demonstrated subtle findings suggestive of DST, specifically some hyperdensities seen within the SSS. Of note there was demonstration of maxillary sinusitis on both the CT done at the referring facility as well as our facility. Clinically, the patient's neurological examination continued to deteriorate. Neurosurgery did not start heparin treatment as they thought the heparin would not be beneficial at this late stage of illness. Their plans were to perform cerebral angiography and possible lysis of clot. The cerebral angiogram, unfortunately, showed no cerebral blood flow. The family withdrew support and no necropsy was

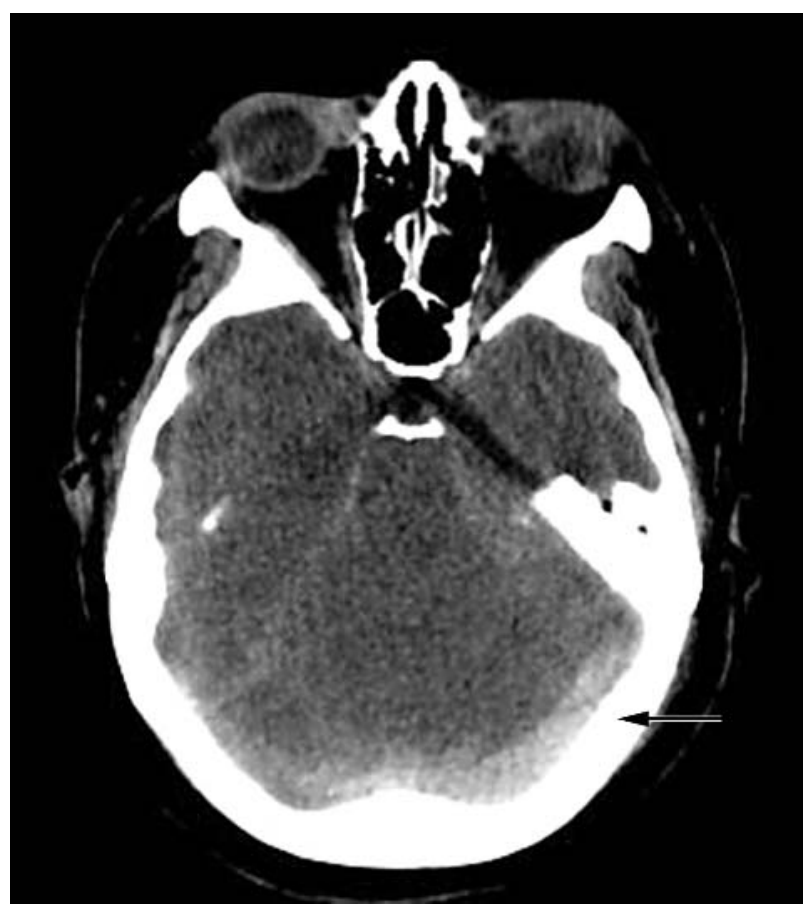

Figure 1 Unenhanced axial CT showing thrombosis of the transverse sinuses.

performed by the family's request. The cause of death listed on the death certificate was dural sinus thrombosis.

\section{DISCUSSION}

Although described in the neurology and neurosurgery literature, DST is not well described in the emergency medicine literature. Major emergency medicine textbooks contain little if any information on this topic. To the best of our knowledge there are only two papers describing DST in the emergency medicine literature: a case report from $1991^{1}$ and a brief case report/discussion in 2002. ${ }^{2}$ Emergency physicians are called upon daily to evaluate severe headaches and other neurological complaints and must know the clinical presentation and the diagnostic tests to make the diagnosis of DST. Furthermore, they must resist the urge to diagnose or believe a diagnosis of BIH without a confirmatory MRI/magnetic resonance venography (MRV) study.

The true incidence of DST is unknown because the generally good prognosis (less than $10 \%$ mortality) and heterogeneous clinical signs probably result in a good percentage of clinically undetected cases. Because of heightened awareness and better diagnostic testing it is being diagnosed more frequently. DST has over 100 recognised aetiologies that encompass all causes of deep vein thrombosis as well as a number of local and regional causes. ${ }^{34}$ The proportion of cases of unknown cause is about $20 \%-30 \%{ }^{3}$ Important distinction is made between infective aetiologies, which comprise $8 \%$ of DST, and non-infective causes. Infective aetiologies are usually staphylococcal infections of the face such as sinusitis. The non-infective aetiologies are principally inflammatory processes such as lupus, Behçet's disease, inflammatory bowel diseases, and any hypercoagulable state such as pregnancy, malignancy, and Factor $\mathrm{V}$ Leiden. ${ }^{5}$ It appears the aetiology of DST in our patient may have been infectious given the maxillary sinusitis seen on CT scan, or it may have been the result of hypercoagulability from oral contraceptive use and smoking.

Presentations are very diverse in DST. Headache is the most frequent symptom and often the presenting one, being 
present in $70 \%$ to $90 \%$ of patients. Focal motor or sensory deficits, dysphagia, seizures, and abnormal mentation each occur in $50 \%$ to $75 \%$ of cases. Papilledema occurs in $12 \%$ to $43 \%$ of patients. ${ }^{3}$ Mode of onset of symptoms is also highly variable ranging from acute presentations (less than 48 hours) to subacute presentations ( 48 hours to 30 days) and finally chronic presentations (greater than 30 days). The most homogeneous pattern of presentation is isolated intracranial hypertension with headache and papilledema, mimicking $\mathrm{BIH}$, and is present in $37 \%$ of cases. ${ }^{3}$ Outcomes are unpredictable. There are acute cases, as ours was, which can have a fulminating course leading to death in a few days whereas others can recover rapidly either with or without sequelae. There are chronic cases that can result in neurological sequelae and others that can recover spontaneously. ${ }^{6}$

In suspected DST, a CT scan with and without contrast injection should be the first neuroimaging study to be performed. Direct signs of DST include the cord sign, the dense triangle, and the empty delta sign. The cord sign, rarely seen on unenhanced CT scan, represents the visualisation of a thrombosed cortical vein. The dense triangle is also rare and represents the spontaneous SSS opacification by freshly congealed blood. The empty delta sign is seen in $30 \%$ of cases on enhanced CT scans and is the result of opacification of collateral veins in the SSS wall, contrasting with the noninjection of the clot inside the sinus. Indirect and nonspecific abnormalities include intense contrast enhancement of falx and tentorium, the presence of small ventricles with swelling, the presence of diffuse low density suggestive of oedema, and haemorrhagic and non-haemorrhagic venous infarcts. ${ }^{3}$ The CT scan is normal in up to $26 \%$ of patients with verified $\mathrm{DST}^{3}$ and up to $54 \%$ of patients that present with isolated intracranial hypertension. ${ }^{7}$ Examination of the cerebral spinal fluid is not terribly helpful in establishing the diagnosis of DST as there is no pathognomonic finding. Abnormalities include raised pressure $(>200 \mathrm{~mm})$, increased protein content, presence of red blood cells, and pleocytosis. ${ }^{6}$ Furthermore, cerebral spinal fluid studies are negative except for raised pressure in $75 \%$ of patients with DST who present with isolated raised intracranial pressure. ${ }^{7}$ MRI combined with MRV have become the radiographic tests of choice for the diagnosis of DST and have replaced the more invasive and expensive cerebral angiography. ${ }^{89}$ MRI alone may result in false positive and false negative readings and the addition of MRV can result in added confidence in the inclusion or exclusion of the diagnosis. ${ }^{10}$ Another option is cerebral CT venography, which has a sensitivity at least as great as MRV. ${ }^{11}$

There are few therapeutic trials of DST resulting in a lack of any clear benefit of any specific treatment option. Although somewhat controversial in efficacy given mixed results from two prospective randomised trials, ${ }^{12}{ }^{13}$ heparin is considered first line treatment in the initial management of DST. This is based on the results of a meta-analysis as well as several retrospective and prospective case series, and influenced by the fact that it seems to be very safe even in the presence of haemorrhagic lesions. ${ }^{4}$ Another option gaining some support is thrombolysis via selective catheterisation of the occluded sinus. It obviously can only be performed in very select centres and it carries an undetermined benefit to risk ratio. It may be indicated in those cases where clinical condition is worsening despite adequate anticoagulation and optimal treatment of the possible causative factors. ${ }^{4}$

DST carries an amazingly diverse array of clinical presentations. It must be in the differential diagnosis of anyone who presents with headaches or other neurological complaints. The emergency physician must maintain a high degree of suspicion for this disease especially in the setting of a patient that may easily be diagnosed as simply having $\mathrm{BIH}$ - a patient presenting with complaints of headache, with a normal head CT and raised intracranial pressure on lumbar puncture. It has been reported that DST can be identified in $26 \%$ of patients presenting with symptoms and signs typical of BIH. ${ }^{14}$ As CT results are often non-specific, MRI with MRV should be the imaging modality of choice, and the diagnosis of BIH should be highly questioned if these studies have not been performed. Treatment begins with unfractionated heparin or low molecular weight heparin as these seem to be safe and effective. Perhaps the outcome of our patient may have been different if DST would have been suspected or diagnosed at the initial hospital visit and appropriate treatment started. Even if a MRI/MRV study was not able to be obtained that day, starting heparin treatment until a definitive diagnosis could be made could have been potentially life saving as there are no reported contraindications to anticoagulating patients with BIH. It is difficult to say if heparin treatment would have been beneficial if started at the transferring facility beause it was so late in the patient's course of illness, however there are reports of dramatic improvement the day after starting heparin treatment in patients with DST who were clinically deteriorating. ${ }^{6}$ This case and subsequent discussion should hopefully convince the emergency physician to strive for early diagnosis and treatment of this illness that is unpredictable in both its presentation and its outcome.

\section{Authors' affiliations}

S Khandelwal, Department of Emergency Medicine, The Ohio State University College of Medicine and Public Health, Columbus, Ohio, USA C D Miller, Department of Emergency Medicine, Wake Forest University School of Medicine, Winston-Salem, NC, USA

Drs Khandelwal and Miller shared equally in the research and writing of the case report.

Correspondence to: Dr S Khandelwal, Department of Clinical Emergency Medicine, The Ohio State University, 167 Means Hall, 1654 Upham Drive, Columbus, Ohio 43210, USA; khandelwal.1@osu.edu

Accepted for publication 7 May 2003

\section{REFERENCES}

1 Pannke TS. Cerebral dural sinus thrombosis. Ann Emer Med 1991;20:813-16.

2 Beeson MS, Vesco JA, Reilly BA, et al. Dural sinus thrombosis. Am J Emerg Med 2002;20:568.

3 Ameri A, Bousser MG. Cerebral venous thrombosis. Neurol Clin 1992;10:87-111.

4 Bousser MG. Cerebral venous thrombosis: nothing, heparin, or local thrombolysis? Stroke 1999;30:481-3.

5 Allroggen H, Abbott RJ. Cerebral venous sinus thrombosis. Postgrad Med J 2000;76:12-15.

6 Bousser MG, Chiras J, Bories J, et al. Cerebral venous thrombosis - a review of 38 cases. Stroke 1985;16:199-213.

7 Biousse V, Ameri A, Bousser MG. Isolated intracranial hypertension as the only sign of cerebral venous thrombosis. Neurology 1999;53:1537-42.

8 Wang AM. MRA of venous sinus thrombosis. Clin Neurosci 1997;4:158-64.

9 Vogl TJ, Bergman C, Villringer A, et al. Dural sinus thrombosis: value of venous MRA for the diagnosis and follow-up. AJR 1994;7:1699-707.

10 Provenzale JM, Joseph GJ, Barboriak DP. Dural sinus thrombosis: findings on CT and MRI imaging and diagnostic pitfalls. AJR 1998;170:777-83.

11 Ozsvath RR, Casey SO, Lunstrin ES, et al. Cerebral venography: comparison of CT and MR projection venography. AJR 1997;169:1699-707.

12 Einhaupl KM, Mehraein S, Haberl, et al. Heparin treatment in sinus venous thrombosis. Lancet 1991;338:597-600.

13 de Bruijn SFTM, Stam J, for the Cerebral Venous Sinus Thrombosis Group. Randomized, placebo-controlled trial of anticoagulant treatment with lowmolecular weight heparin for cerebral sinus thrombosis. Stroke 1999;30:484-8.

14 Leker RR, Steiner I. Features of dural sinus thrombosis simulating pseudotumor cerebri. Eur J Neurol 1999;6:601-4. 


\title{
Meningococcal septicaemia: do not be reassured by normal investigations
}

\author{
P R E Jarvis, K N Wilkinson
}

Emerg Med J 2004;21:248-249. doi: 10.1136/emj.2003.007955

This paper reports a case of meningococcal septicaemia. This case shows that normal investigations may provide the unwary clinician with an unfounded reassurance when dealing with children with this serious infection.

A general practitioner saw a 5 month old girl at morning surgery. She had been seen earlier in the week with diarrhoea and vomiting. This was thought to be attributable to viral gastroenteritis. The gastrointestinal symptoms had settled, but the child had now developed a fever and was becoming increasingly irritable. The child was reviewed again after two hours. She was not settling so the GP arranged admission to the paediatric acute admission unit at the local district general hospital.

On arrival the baby was alert. Her temperature was $38.4^{\circ} \mathrm{C}$, respiratory rate was 64 breath/min, pulse was 170 beat $/ \mathrm{min}$. and her oxygen saturations were $96 \%$ on air. Her breathing was noisy because of nasal secretions. The chest was clear and heart sounds were normal. Her abdomen was soft and non-tender. Her mucus membranes were moist and the capillary refill was less than two seconds centrally. Two $3 \mathrm{~mm}$ diameter pale, blanching, erythematous macules were noted in her left flank.

A diagnosis of viral upper respiratory tract infection with a non-specific rash was made. Paracetamol was given to treat the fever and intravenous fluids were given to prevent dehydration.

Blood investigations showed $\mathrm{Na}^{+} 136 \mathrm{mmol} / \mathrm{l}, \mathrm{K}^{+}$ $3.9 \mathrm{mmol} / \mathrm{l}$, Ur $1.0 \mathrm{mmol} / \mathrm{l}, \mathrm{HCO}_{3}{ }^{-} 20 \mathrm{mmol} / \mathrm{l}$. C reactive protein (CRP) was less than $10 \mathrm{mg} / \mathrm{l}$. Unfortunately, the full blood count sample clotted during transit to the laboratory. A lumbar puncture was performed to exclude meningitis. Cerebrospinal fluid was clear and colourless. Microscopy and biochemistry of cerebrospinal fluid was normal.

Within the next hour the patient was reviewed by the oncall consultant who felt that this could be meningococcal septicaemia. Blood was taken for culture and polymerase chain reaction for meningococcus. Intravenous cefotaxime was given followed by a fluid bolus.

Over the next two hours she started to deteriorate rapidly. She responded to voice and non-blanching purpura developed on her torso, face, and neck. Capillary refill was now five seconds. Supplemental oxygen was given. A capillary sample was sent for blood gas analysis. This showed $\mathrm{pH} 6.91$, $\mathrm{pO}_{2} 7.64 \mathrm{KPa}, \mathrm{pCO}_{2} 9.26 \mathrm{KPa}, \mathrm{HCO}_{3} 13.5 \mathrm{mmol} / \mathrm{l}$ base excess $-19.9 \mathrm{mmol} / \mathrm{l}$ on 10 litres of oxygen per minute. Blood was sent for clotting screen, which showed prothrombin time $19 \mathrm{~s}$ and activated partial thromboplastin time 105 s. A further fluid bolus and $4.2 \%$ sodium bicarbonate solution were given.
Fresh frozen plasma was also given to correct the abnormal clotting.

The child was now beginning to tire. Her pulse was 194 beat/min, respiratory rate was 73 , and blood pressure was 69/ 47. Dobutamine was started via a peripheral line and a rapid sequence induction was performed by the on-call consultant anaesthetist.

Two hours after starting ventilation the child had an episode of sinus bradycardia that was treated with intravenous atropine. She responded initially but 30 minutes later she had an asystolic arrest and never recovered. This 5 month old girl died within nine hours of admission.

Postmortem examination was declined. Blood cultures grew group B meningococcus confirming the diagnosis of meningococcal infection.

\section{DISCUSSION}

Despite treatment that was not far removed from current guidelines, a febrile but apparently well child, with a normal CRP and lumbar puncture, who was frequently reviewed by a paediatric senior house officer, consultant, and experienced paediatric nurse died from meningococcal septicaemia within nine hours of presentation.

In a tragic way this case demonstrates a number of learning points. The initial clinical features can be vague. Our catchment area contains about 300 febrile children every day. The task of identifying high risk patients is obviously difficult. We suggest that all children who have a feverish illness without a clear infective focus should be suspected of having meningococcal septicaemia. These initial diagnostic difficulties should teach us to become sympathetic for clinicians who get caught out.

At presentation the rash consisted of two blanching macules. This is not the characteristic rash that is associated with meningococcal septicaemia. However, in the early stages of disease a blanching maculopapular rash can occur in about $17 \%$ of patients. ${ }^{1}$ The confidence of the clinician should not be placed in this clinical sign alone.

In this case all initial investigations were normal. This can easily provide the unsuspecting clinician with ungrounded reassurance. Bonsu and Harper found that $64 \%$ of 170 patients with bacterial meningitis had a normal white cell count. $^{2}$ Although a result in this case was not available, the findings of Bonsu and Harper emphasise that the full blood count can be normal in children with serious infections. Borschsenius et al suggest that CRP can be valuable in differentiating between meningococcal disease and other diseases. ${ }^{3}$ However, the fact that in this case the CRP at presentation was less than $10 \mathrm{mg} / \mathrm{l}$ suggests this should be exercised with caution.

In conclusion, meningococcal septicaemia can initially be difficult to diagnose. Investigations, in particular CRP, may be normal in the early stages of the disease. 
All diagnosis depends on a combination of three processes; history with examination, investigation, and observation. At each stage anxieties may be raised or reduced. Results from investigations should be used to complement the clinical findings rather than replace assessment and re-evaluation of the patient.

\author{
Authors' affiliations \\ P R E Jarvis, Accident and Emergency Department, Bradford Royal \\ Infirmary, Bradford, UK \\ K N Wilkinson, Department of Paediatrics, Airedale General Hospital, \\ Keighly, West Yorkshire, UK
}

Correspondence to: Dr P R E Jarvis, Accident and Emergency Department, Bradford Royal Infirmary, Bradford, West Yorkshire, UK; prejarvis@yahoo.com

Accepted for publication 26 July 2003

\section{REFERENCES}

1 Olesch CA, Knight GJ. Invasive meningococcal infection in Western Australia. J Paediatr Child Health 1999:35:42-8.

2 Bonsu BK, Harper MB. Utility of the peripheral blood white cell count for identifying sick young infants who need lumbar puncture. Ann Emerg Med 2003;41:206-14.

3 Borschsenius F, Bruun JN, Michaelsen TE, et al. Serum C-reactive protein in systemic infections due to Neisseria meningitidis. Norwegian Institute of Public Health Annals 1986;9:15-21.

\section{Lignocaine toxicity; a complication of local anaesthesia administered in the community}

\section{J Donald, S Derbyshire}

Local anaesthetic agents are among the most commonly used drugs in the emergency department. A case is reported of a complication arising from systemic toxicity after the injection of lignocaine (lidocaine). Emergency practitioners should maintain a high level of vigilance for the symptoms of toxicity after local anaesthetic administration. Particular care should be taken when calculating the maximum safe dose for young children.

A 7 week old male infant was brought from home by a paramedic crew to the emergency department having undergone a circumcision by the family general practitioner. A dorsal penile nerve block (DPNB) was the analgesic technique used and lignocaine (lidocaine) was the anaesthetic agent. The parents of the infant phoned for an ambulance after a series of generalised seizures. The onset of these was about 20-30 minutes after the block had been administered.

On examination, the infant was able to maintain his airway; he was breathing spontaneously and had a capillary refill time of less than two seconds. He was unresponsive, hypertonic, and generalised seizure activity was noted. There was some fresh blood around the base of the penis, but no evidence of any rash or fever.

The first line treatment was oxygen and intravenous benzodiazepines at the appropriate dose.

On further questioning, we gathered that $3 \mathrm{ml}$ of $1 \%$ lidocaine $(30 \mathrm{mg}$ ) had been used for the DPNB and using the Oakley chart we estimated the infant's weight to be $4.5 \mathrm{~kg}$. The maximum safe dose of lidocaine is $3 \mathrm{mg} / \mathrm{kg}$ (table 1) and therefore the maximum safe dose for this patient was calculated to be $13.5 \mathrm{mg}$ ( $1.35 \mathrm{ml} 1 \%$ lidocaine). A diagnosis of lidocaine toxicity was made.

Supportive treatment was continued for 45 minutes and during this time, the infant remained generally hypertonic but with no further seizure activity. After one hour, his tone had returned to normal and his condition stabilised. Two hours after he presented to the emergency department, he was fit for transfer to the ward.

The remainder of his stay was uneventful and he was permitted home the following day. At follow up two months later, there were no obvious ill effects and there were no developmental abnormalities.

\section{DISCUSSION}

Lidocaine is one of the most widely used local anaesthetic agents in the emergency department. It has been used safely and effectively for almost every possible type of local anaesthetic procedure. It has a rapid onset and it is effective for about 30-60 minutes in its plain form (or up to 90 minutes when used with a vasoconstrictor).

Lidocaine is a tertiary amine that is an amide derivative of diethylaminoacetic acid. Allergic reactions to the amide group of local anaesthetics are extremely rare and the vast majority of adverse reactions result from systemic toxicity. The symptoms are an extension of the drug's pharmacological action.

There are few reports of local anaesthetic toxicity in infants and children. However, seizures, arrhythmias, cardiac arrest, and transient neuropathic symptoms have been reported. ${ }^{1}$ Lidocaine toxicity has been reported after subcutaneous administration, oral administration, and intravascular injection..$^{2-4}$

A retrospective study of 1358 circumcised male infants revealed that 1022 had a DPNB as the anaesthetic technique. ${ }^{5}$ In these, there were no reports of local anaesthetic toxicity. A meta-analysis of injection related adverse effects during DPNB by injected lidocaine revealed no reports of systemic toxicity from injected local anaesthesia. ${ }^{6}$ Similarly, a study of 133 patients to evaluate the efficacy and safety of intravenous regional anaesthesia revealed no reports of lidocaine toxicity. ${ }^{7}$ In this study, intravenous regional anaesthesia was used in the treatment of unilateral closed fractures and dislocations of forearm or wrist in children and $0.5 \%$ lidocaine solution ( $3 \mathrm{mg} / \mathrm{kg}$ intravenously) was the agent used.

Despite the apparent safety of lidocaine, it is a widely held view that extra care should be taken when administering local anaesthesia to young children as it can be easy to overestimate the dose to weight ratio.

Peak blood levels of lidocaine usually occur 10-25 minutes after injection. This is the point at which the toxic effects are most likely to be observed. The onset of symptoms is faster if accidental intravascular injection has occurred. The first symptoms and signs of local anaesthetic toxicity are usually 
Table 1 Chart showing the maximum safe dose of anaesthetic

\begin{tabular}{lll}
\hline Local anaesthetic & Maximimum dose & Duration of action (h) \\
\hline Bupivicaine & $2 \mathrm{mg} / \mathrm{kg}$ & $2-4$ \\
Lidocaine & $3 \mathrm{mg} / \mathrm{kg}$ & 1 \\
Lidocaine/vasoconstrictor & $5 \mathrm{mg} / \mathrm{kg}$ & 1.5 \\
(avoid near end organ) & $6 \mathrm{mg} / \mathrm{kg}$ & 1.5 \\
Prilocaine & & 1.5 \\
\hline
\end{tabular}

neurological with numbness of the mouth and tongue. Shortly afterwards, there is the onset of tinnitus, confusion, seizures, and potentially coma.

Cardiovascular toxicity usually manifests itself as tachycardia and hypertension but with increasing toxicity bradycardia and hypotension occur. Ventricular arrythmias and cardiac arrest are also known side effects. ${ }^{4}$

The treatment of local anaesthetic toxicity is essentially supportive. The airway should be maintained and oxygen should be administered. Monitoring of blood pressure and ECG is mandatory. If convulsions occur they should be controlled with benzodiazepines along established guidelines. Bradycardia is usually self limiting, but if persistent and associated with hypotension, atropine and cardiac pacing may be necessary. The symptoms of toxicity persist as long as the plasma concentrations remain above the therapeutic index. Seventy per cent of the dose is metabolised in the liver and less than $10 \%$ is excreted unchanged in the urine with an excretion half life of 90-110 minutes. The toxicity from lidocaine is of shorter duration than from other agents with a longer half life, for example, bupivicaine.

In conclusion, this case highlights the need for vigilance for symptoms of systemic toxicity when administering any local anaesthetic. Particular care must be taken when they are used in young children. It is essential that the weight of the child is measured before starting any procedure that entails local anaesthesia. If the weight cannot be measured, then an estimate should be made using well established guidelines.

\section{Authors' affiliations}

M J Donald, S Derbyshire, Department of Emergency Medicine, Manly Hospital, Sydney, Australia

Correspondence to: Dr M J Donald, Balnakeil, 31 a Strathkinness High Road, St Andrews, Fife KY16 9UA, UK; mikedonald25@hotmail.com

Accepted for publication 23 September 2003

\section{REFERENCES}

1 Gunter JB. Benefit and risk of local anesthetics in infants and children. Paediatr Drugs 2002;4:649-72.

2 Alfano SN, Leight MJ, Skiendzielewski JJ. Lidocaine toxicity following subcutaneous administration. Ann Emerg Med 1984;13:465-7.

3 Smith M, Wolfram W, Rose R. Toxicity seizures in an infant caused by (or related to) oral viscous lidocaine use. J Emerg Med 1992;10:587-90.

4 Brown DL, Skiendzielewski JJ. Lidocaine toxicity. Ann Emerg Med 1980;9:627-9.

5 Fotaine $\mathbf{P}$, Dittberner D, Scheltema KE. The safety of dorsal penile nerve block for neonatal circumcision. J Fam Pract 1994;39:243-8.

6 Taddio A. Pain management for neonatal circumcision. Paediatr Drugs 2001:3:101-11.

7 Colizza WA, Said E. Intravenous regional anesthesia in the treatment of forearm and wrist fractures and dislocations in children. Can J Surg 1993;36:225-8.

\title{
Delayed postanoxic encephalopathy after carbon monoxide poisoning
}

\author{
O Y Kwon, S P Chung, Y R Ha, I S Yoo, S W Kim
}

Emerg Med J 2004;21:250-251. doi: 10.1136/emj.2002.002014

Delayed postanoxic encephalopathy causes deterioration and relapse of cognitive ability and behavioural movement a few weeks after complete recovery from initial hypoxic injury. A case is reported of delayed postanoxic encephalopathy after carbon monoxide poisoning, which was diagnosed with diffusion weighted magnetic resonance imaging. The literature is also reviewed.

A 65 year old man was admitted to the emergency department (ED) with memory impairment and movement disturbance. One month previously he had presented to our ED with a drowsy mental status because of carbon monoxide (CO) poisoning after he had attempted suicide by a briquette fire. However, he had recovered with normobaric oxygen therapy that resulted in a decrease in the blood carboxyhaemoglobin level from $30.5 \%$ on arrival to $2.3 \%$ just before discharge. On his second presentation, he had no other remarkable medical history. His blood pressure was $120 / 80 \mathrm{~mm} \mathrm{Hg}$, heart rate $82 / \mathrm{min}$, and respiratory rate $24 / \mathrm{min}$. He was alert, comparatively well coordinated, but slightly disoriented with regard to time and person. $\mathrm{He}$ showed no neurological abnormality apart from parkinsonian movement.

Diffusion weighted magnetic resonance imaging (DWMRI) showed diffuse high signal intensity in both periventricular and deep white matter (fig 1). He was admitted to the neurology ward for supportive care, and discharged on the

Abbreviations: $E D$, emergency department; $C O$, carbon monoxide; DPE, delayed postanoxic encephalopathy; DWMRI, diffusion weighted magnetic resonance imaging 


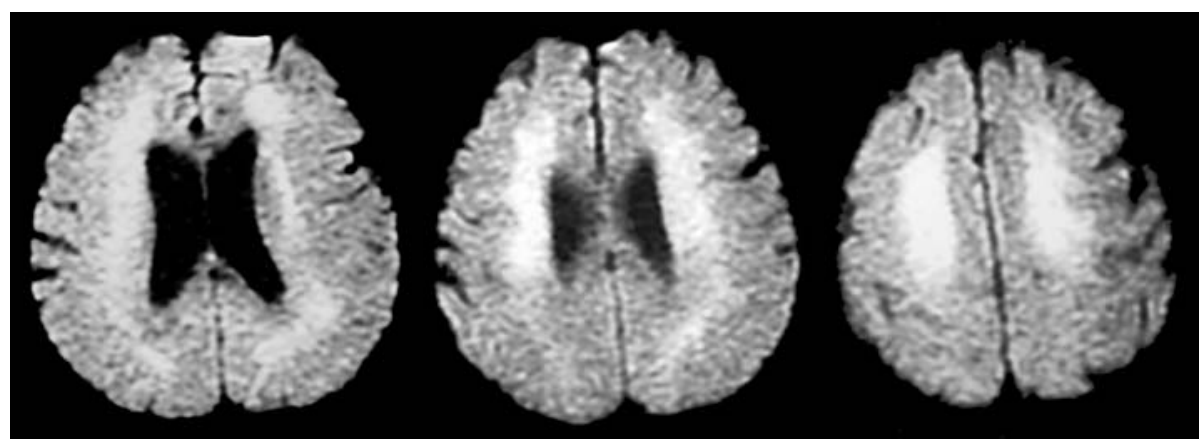

Figure 1 Diffusion weighted magnetic resonance imaging shows abnormal high signal intensity in both periventricular and deep white matter.

17th hospital day without significant improvement. Two months after the second discharge, his symptoms were slightly improved, but mild rigidity and gait disturbance still remained.

\section{DISCUSSION}

Many cases of CO poisoning, whether incidental or accidental, initially visit the ED. Most of them recover well without any complication with hyperbaric or high oxygen therapy. But $10 \%$ to $30 \%$ of them revisit hospital with delayed neuropsychiatric sequelae, symptoms such as cognitive and personality changes, incontinence, dementia, and psychosis. ${ }^{1}$ Parkinsonism is also one of the features of delayed CO encephalopathy, and has been reported to occur in $9.5 \%$ of CO poisoned patients. ${ }^{2}$ The exact mechanism is uncertain, but a magnetic resonance spectroscopic study revealed white matter damage that was reversible in accordance with complete recovery from parkinsonism. ${ }^{3}$ The diagnosis is easily made by typical symptoms such as short step gait, hypokinesia, masked face, and increased muscle tone. ${ }^{2}$

We performed the DWMRI in this case to confirm the diagnosis of DPE. The DWMRI is a new generation magnetic resonance imaging sequence based on the translational movement of water. It is becoming more common in the ED because of high sensitivity for acute ischaemic stroke as well as short scanning time. ${ }^{4}$ The DWMRI showed hyperintense signals in the periventricular and deep white matter, and the high signal intensity means cytotoxic oedema may be differentiated from apoptosis and triggered by hypoxia. ${ }^{5}$ We could not obtain a follow up DWMRI after improvement. But a serial imaging study showed gradual normalisation of the high signal lesion.

The recovery from DPE after CO poisoning occurs in 50\%$75 \%$ within one year. ${ }^{6}$ It seems that no specific treatment is required for DPE. Levodopa and anticholinergic drugs have been reported ineffective to reverse the parkinsonian feature. ${ }^{2}$ It has been reported in a small randomised trial that the hyperbaric oxygen treatment for acute CO poisoning could decrease the incidence of delayed neuropsychiatric sequelae. ${ }^{7}$ But, a recent animal study failed to demonstrate the neuroprotection effect as compared with the normobaric oxygen therapy. ${ }^{8}$ Clinical status or carboxyhaemoglobin level on initial CO poisoning could not predict the occurrence of DPE. The most common computed tomography finding in several cases of CO poisoning was low density in the cerebral white matter followed by lesions of the globus pallidi. Some investigators reported that there was significant correlation between the cerebral white matter changes in the initial CT scan and the development of delayed neurological sequelae after acute $\mathrm{CO}$ poisoning. ${ }^{\circ}$

Most CO poisoning patients present to the ED. Thus emergency doctors should be familiar with the possibility of DPE after apparent complete recovery from acute CO poisoning.

\section{Authors' affiliations}

O Y Kwon, Department of Anatomy, College of Medicine, Chungnam National University, Daejeon, Republic of Korea

S P Chung, I S Yoo, S W Kim, Department of Emergency Medicine, Chungnam National University Hospital, Daejeon, Republic of Korea Y R Ha, Department of Emergency Medicine, Daejin Medical Centre, Pundang Jesaeng General Hospital, Kyunggido, Republic of Korea

Correspondence to: Dr S W Kim, Department of Emergency Medicine, Chungnam National University Hospital, Daejeon, 301-721, Republic of Korea; emfire@cnuh.co.kr

Accepted for publication 13 May 2003

\section{REFERENCES}

1 Ernst A, Zibrak JD. Carbon monoxide poisoning. N Engl J Med 1998;339:1603-8.

2 Choi IS. Parkinsonism after carbon monoxide poisoning. Eur Neurol 2002;48:30-3

3 Sohn YH, Jeong Y, Kim HS, et al. The brain lesion responsible for parkinsonism after carbon monoxide poisoning. Arch Neurol 2000;57:1214-8

4 Chung SP, Ha YR, Kim SW, et al. Diffusion-weighted MRI as a screening tool of stroke in the ED. Am J Emerg Med 2002;20:327-31.

$5 \mathrm{Kim}$ HY, Kim BJ, Moon SY, et al. Serial diffusion-weighted MR imaging in delayed postanoxic encephalopathy. A case study. J Neuroradiol 2002;29:211-15

6 Choi IS. Delayed neurologic sequelae in carbon monoxide intoxication. Arch Neurol 1983:40:433-5.

7 Thom SR, Taber RL, Mendiguren II, et al. Delayed neuropsychologic sequelae after carbon monoxide poisoning: prevention by treatment with hyperbaric oxygen. Ann Emerg Med 1995;25:474-80.

8 Gilmer B, Kilkenny J, Tomaszewski C, et al. Hyperbaric oxygen dose not prevent neurologic sequelae after carbon monoxide poisoning. Acad Emerg Med 2002;9:1-8.

9 Choi IS, Kim SK, Choi YC, et al. Evaluation of outcome after acute carbon monoxide poisoning by brain CT. J Korean Med Sci 1993;8:78-83. 


\title{
Cocaine induced prolongation of the QT interval
}

\author{
D Taylor, D Parish, L Thompson, M Cavaliere
}

Emerg Med J 2004;21:252-253. doi: 10.1136/emj.2002.003251

$\mathrm{P}$ rolongation of the QT interval is a serious electrocardiogram finding because of its association with torsades de pointes and sudden cardiac death. ${ }^{1}$ Both congenital and acquired factors can lead to abnormal lengthening of the QT interval. Six types of congenital long QT syndrome (LQTILQT6) have been described, each involving mutations in genes encoding potassium or sodium transmembrane channel proteins. ${ }^{2}$

Acquired causes of QT prolongation include hypokalaemia, hypomagnesaemia, hypocalcaemia, human immunodeficiency virus infection, and myocardial ischaemia. ${ }^{2-4}$ Numerous drugs have also been found to cause prolongation of the QT interval. A listing of these drugs can be found on a web site (http://www.qtdrugs.org). The main membrane channel these drugs affect is the human ether-a-go-gorelated gene (HERG) encoded potassium channel; congenital mutations involving this gene lead to the LQT2 type of the inherited long QT syndromes. ${ }^{25}$

Cocaine use has been associated with many cardiac complications including ventricular arrhythmias and sudden death, ${ }^{67}$ and cocaine induced torsades de pointes in patients with idiopathic long QT syndrome has been described in two case reports. ${ }^{8}$ A case report of cocaine induced QT prolongation (in the absence of congenital long QT syndrome) was published in $1997 .{ }^{10}$ In a study of 45 patients (with a history of chest pain, somnolence, or disorientation) admitted to the hospital after cocaine use, Gamouras et al showed that the QT interval was increased in patients with and without chest pain and that those with chest pain had greater QT prolongation. ${ }^{11}$ Cocaine and its metabolites, like many other substances shown to prolong the QT interval, have been shown to block HERG encoded potassium channels. ${ }^{12}$

\section{CASE REPORT}

We present the case of a 37 year old man with a history of chest pain occurring after a three day crack cocaine binge.
The patient, after smoking over 200 rocks of crack cocaine in 72 hours, attempted a several mile walk toward a destination at which he was to obtain more money for cocaine purchases. Nearing the end of his walk, the patient developed severe chest pain and shortness of breath and phoned for an ambulance. The patient's chest pain and dyspnea resolved before the ambulance arrived at the hospital. The patient had no medical history and no history of syncope or palpitation. He described himself as being "in good shape" and reported he exercised regularly. He had no family history of sudden death. He was not taking any prescription or over the counter medications and gave a history of occasional alcohol and marijuana use.

Physical examination revealed an anxious AfricanAmerican man who had an athletic appearance. The rest of the examination was unremarkable. The patient's heart rate was 56 beat/min, and his blood pressure was 123/63 mm Hg. Serum electrolytes were within normal limits, and a urine drug screen was positive for cocaine and negative for other substances. Cardiac iso-enzymes were within normal limits and remained so on serial analysis. An initial electrocardiogram revealed $\mathrm{a} \mathrm{QT}_{\mathrm{c}}{ }^{*}$ of $621 \mathrm{~ms}$ (fig 1). A repeat electrocardiogram two hours later revealed a $\mathrm{QT}_{\mathrm{C}}$ of $605 \mathrm{~ms}$. The patient was admitted for observation and was placed on telemetry. The patient's third and fourth electrocardiograms, taken 7 and 15 hours after the initial electrocardiogram, revealed $\mathrm{QT}_{\mathrm{C}} \mathrm{S}$ equal to $530 \mathrm{~ms}$ and $543 \mathrm{~ms}$, respectively. Calculation of $\mathrm{QT}_{\mathrm{C}}$ from the patient's telemetry rhythm strips revealed that the $\mathrm{QT}_{\mathrm{c}}$ had returned to normal at around 18 hours after the initial electrocardiogram. The patient remained asymptomatic throughout this period and was

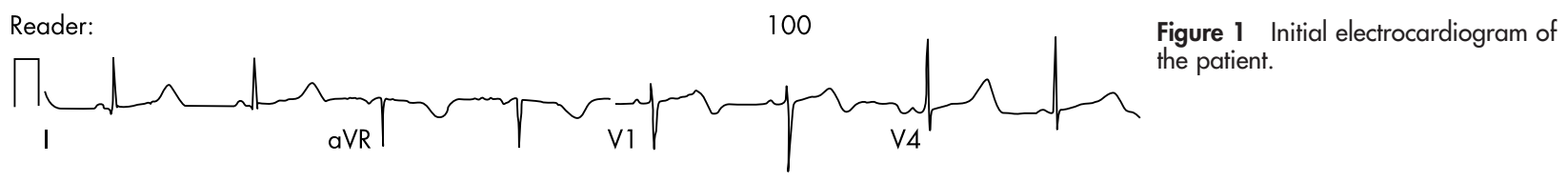

*QTc is the QT interval corrected for the patient's heart rate. QTc $=(Q T) /$ ( $R R$ ), where RR is the distance between consecutive $R$ waves on the electrocardiogram.
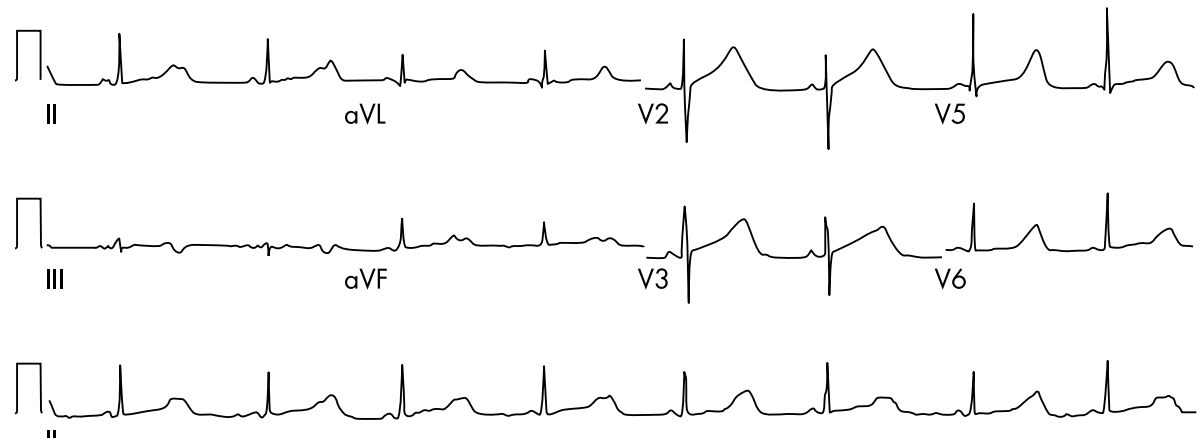
discharged from the hospital in good condition after appropriate substance misuse counselling. A follow up electrocardiogram, one month later, revealed a normal $\mathrm{QT}_{\mathrm{C}}$ interval of $453 \mathrm{~ms}$. The patient stated he had been free of cocaine since discharge.

\section{DISCUSSION}

We hope the case we present not only will reinforce the need for close cardiac monitoring in patients who have used cocaine but also will remind physicians that cocaine can exert dangerous electrophysiological effects on the heart that are not necessarily related to the drug's inducement of a hyperadrenergic or cardioischaemic state. It is important to note that our patient, though anxious, was not tachycardic or hypertensive, and there was no evidence of cardiac ischaemia. We also hope that the information presented will encourage physicians to exercise extreme caution in the prescription of QT prolonging drugs to patients who have recently used cocaine or have a history of cocaine misuse.

\section{Authors' affiliations}

D Taylor, D Parish, L Thompson, M Cavaliere, Mercer University School of Medicine, Department of Internal Medicine, Macon, USA

Conflicts of interest: none declared.
Correspondence to: Dr D Taylor, 3901 Northside Drive, Apt 4 H, Macon, GA 31210, UK; derrickwtaylor@earthlink.net

Accepted for publication 17 January 2003

\section{REFERENCES}

1 Smith WM, Gallagher JJ. "Les torsades de pointes": an unusual ventricular arrythmia. Ann Intern Med 1980;93:578-84.

2 Khan IA. Long QT syndrome: diagnosis and management. Am Heart J 2002;143:7-14.

3 Curry P, Fitchett D, Stubbs W, et al. Ventricular arrhythmias and hypokalaemia. Lancet 1976;ii:231-3.

4 Kocheril AG, Bokhari SAJ, Batsford WP, et al. Long $\mathrm{QT}_{\mathrm{c}}$ and torsades de pointes in human immunodeficiency virus disease. Pacing Clin Electrophysiol 1997:20:2810-16.

5 Mitcheson JS, Chen J, Lin M, et al. A structural basis for drug-induced long QT syndrome. Proc Natl Acad Sci USA 2000;97:12329-33.

6 Benchimol A, Bartall H, Desser KB. Accelerated ventricular rhythm and cocaine abuse. Ann Intern Med 1978;88:519-20.

7 Nanji AA, Filipenko JD. Asystole and ventricular fibrillation associated with cocaine intoxication. Chest 1984;85:132-3.

8 Singh N, Singh HK, Singh PP, et al. Cocaine-induced torsade de pointes in idiopathic long Q-T syndrome. Am J Ther 2001;8:299-302.

9 Schrem SS, Belsky P, Schwartzman D, et al. Cocaine-induced torsades de pointes in a patient with the idiopathic long QT syndrome. Am Heart J 1990;120:980-4.

10 Perera R, Kraebber A, Schwartz MJ. Prolonged QT interval and cocaine use. J Electrophysiol 1997;30:337-9

11 Gamouras GA, Monir G, Plunkitt K, et al. Cocaine sbuse: pepolarization abnormalities and ventricular arrhythmias. Am J Med Sci 2000;320:9-12.

12 Ferreira S, Crumb WJ, Carlton CG, et al. Effects of cocaine and its major metabolites on the HERG-encoded potassium channel. J Pharmacol Exp ther $2001 ; 299: 220-6$.

\section{Herbal mind altering substances: an unknown quantity?} C Doughty, A Walker, J Brenchley

$\mathrm{H}$ erbal drugs are increasingly marketed as a "safe" alternative to illicit drugs. The variety of constituents in these compounds and their potential pharmacological activity can present difficulties for the emergency physician in management of intoxicated patients. After a case at a recent music festival, we present a case report and review of herbal compounds.

\section{CASE REPORT}

A 17 year old women was brought to the festival medical base by first aid ambulance. Friends said she had taken herbal drugs ("road runners") and alcohol. She was fully conscious, hyperventilating, tachycardic (pulse $155 \mathrm{bpm}$ ) with dilated pupils $(6 \mathrm{~mm})$. She became increasingly agitated and five minutes after arrival had a grand mal seizure, which was terminated with $5 \mathrm{mg}$ intravenous diazemuls. She was transferred to a local emergency department and on arrival was fully alert, but still tachycardic. She was also noted to have nystagmus at this time. Routine blood tests (full blood count, urea, and electrolytes) were normal. She had no previous history of seizures. After a period of four hours of observation, she was discharged home with a responsible adult.

There is little awareness among healthcare professionals of these drugs and possible side effects of the constituents. Using a research grant from BAEM, a selection of these "herbal" drugs (including the type ingested by our patient) have been analysed and some of the results are presented below. We also present a review of the ingredients listed on the product information.

\section{CHEMICAL ANALYSIS}

The predominant ingredients in the seven products tested are ephedrine and caffeine. Varying quantities of herbal substances may also be present, but cannot be identified on the spectrograph trace using current information. Figure 1 shows the gas chromatography mass spectrometry for the herbal product taken by the patient.

Peaks at 101 and 195 represent ephedrine and caffeine respectively. The peak at 285 is bupivacaine, which is used as a standard. The other peaks correspond to methyl norhexadeconoate (scan no 214), palmitic acid butyl ester (scan no 222), oleic acid butyl ester (scan no 244), and oleic acid butyl ester (scan no 252). On average each capsule contained $16 \mathrm{mg}$ of ephedrine and $0.6 \mathrm{mg}$ of caffeine.

No illicit drugs were found in any of the samples. The drugs tested for are amphetamine and derivatives, ecstasy and derivatives, ketamine, lidocaine, cocaine, methadone, codeine, dihydrocodeine, morphine, diamorphine, papaverine, propoxyphene, narcotine and derivatives, tetrahydrocannabinol and cannabidiol, diazepam, temazepam and flunitrazepam.

\section{INGREDIENTS}

Most of these products list an array of herbal constituents, which will be unfamiliar to most healthcare professionals. These include: 


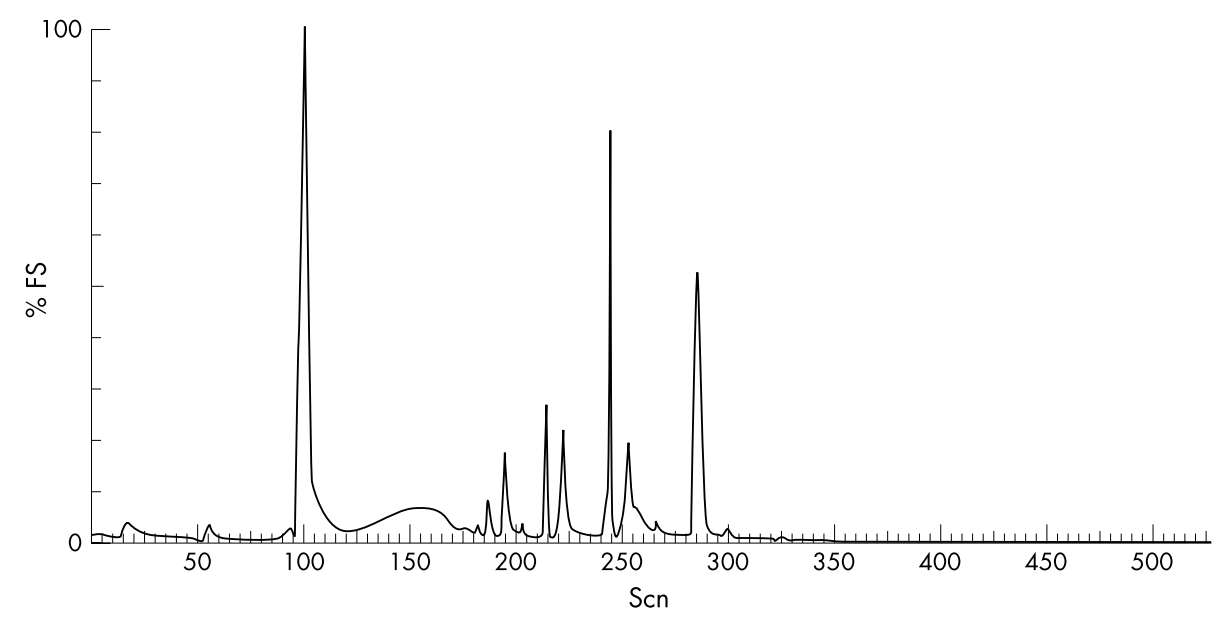

Figure 1 Gas chromatography mass spectrometry for the herbal product taken by the patient.

\section{Sweetflag (Acorus calamus)}

Has been shown to be carcinogenic in rats and mutagenic in bacteria. ${ }^{1}$ There is also a risk of hypertensive reactions if taken concomitantly with monoamine oxidase inhibitors.

\section{Hawaiian baby woodrose (Argyria nervosa)}

Despite claims that this has similar properties to LSD (but only a tenth as strong), ${ }^{2}$ studies report little in the way of psychedelic effects. $^{3}$

\section{Ginseng (Eleutherococcus senticosus)}

There is little evidence of beneficial effects, but with long term use an abuse syndrome is seen causing hypertension, sleeplessness, skin eruptions, oedema, and early morning diarrhoea. ${ }^{4}$

\section{Morning glory (Ipomoea violacea)}

This acts in a similar manner to LSD though at different sites in the central nervous system. ${ }^{5}$

\section{Guarana (Paullina cupana)}

This contains mainly caffeine together with theophyllines and theobromides and so ingestion may be problematic in those with anxiety or cardiovascular disorders. ${ }^{6}$ There is also a potential for toxicity if taken in combination with prescribed theophylline.

\section{Kava (Piper methysticum)}

Kava produces mild euphoric effect and is a good anxiolytic. ${ }^{7-9}$ It is used in the Pacific Islands where long term use causes a characteristic dermopathy. It may cause uraemia, lymphopenia, thrombocytopenia, hyperbilirubinaemia, and haematuria. ${ }^{8}$ Kava may cause loss of uterine tone and customers are advised to abstain if pregnant or breast feeding. ${ }^{8}$ It has been shown to be hepatotoxic and has recently been withdrawn from the British market although may still appear in some herbal products. ${ }^{10}$

\section{Saw palmetto (Serenoa repens)}

This is widely used for benign prostatic hypertrophy and is thought to be a $5 \alpha$-reductase inhibitor. It is claimed to have aphrodisiac properties, though this has not been noted by patients prescribed the drug. It also has some antiinflammatory properties.

\section{Bala (Sida cordifolia)}

Bala has analgesic and anti-inflammatory properties. The manufacturers claim it to be a source of ephedrine (http:// www.herbalhighs.com) although studies have found little evidence for this. ${ }^{11}$ It can cause hypoglycaemia by stimulating release of insulin. ${ }^{12}$

\section{DISCUSSION}

In the emergency department the patient's symptoms were initially thought to be attributable to alcohol alone, however some of the effects may have been attributable to caffeine or ephedrine, or both. The possibility of other legal or illicit substances having been taken should always be considered.

Most of the products described here have little in the way of psychedelic effects. They may however have potentially serious interactions with other prescribed medication. Coingestion of these products with alcohol (most commonly) or with illicit drugs may change their presentation. Alcohol could exacerbate the effects of dehydration and hypoglycaemia. The analysis of the products we have undertaken shows them to be mainly composed of caffeine and ephedrine. The quantities however are less than in other proprietary products and will therefore be unlikely to have significant adverse effects, unless taken in significant numbers. Supportive management is appropriate. Benzodiazepines may be used to control seizure activity. Hypotension should be treated with fluids and positioning. Hypertension and arrhythmias should be managed conservatively, but sodium nitroprusside and phentolamine have both been used for blood pressure control if necessary. ${ }^{13}$ Benzodiazepines are also appropriate for acute drug induced psychoses. ${ }^{14}$

In conclusion, although these products seem to contain a cocktail of obscure products, serious side effects are unlikely from the concentrations present. Management of these patients is supportive.

\section{ACKNOWLEDGEMENTS}

Forensic Science Service Laboratory, Chorley, British Association of Accident and Eemrgency Medicine

\section{Authors' affiliations}

C Doughty, Emergency Department, Arrowe Park Hospital, Upton, Merseyside, UK

A Walker, Emergency Department, Pontefract General Infirmary, Pontefract, UK

J Brenchley, Emergency Department, Barnsley District General Hospital, Barnsley, UK

Correspondence to: Dr A Walker, Emergency Department, Pontefract General Infirmary, Friarwood Lane, Pontefract WF8 1PL, UK; alison.walker1@virgin.net

Accepted for publication 22 April 2003 


\section{REFERENCES}

1 Ernst E, De Smet PAGM. Risks associated with complementary therapies. In: Meyler's side effects of drugs. 13th edn. St Louis: Elsevier Science, 1996.

2 Shawcross WE. Recreational use of ergoline alkaloids from Argyria nervosa. J Psychoactive Drugs 1983;15:251-9.

3 Eileen, Richard. Letter to the editor. High Times 10 Jan, 1977.

4 Dowling EA, Redondo DR, Branch JD, et al. Effect of Eleutherococcus senticosus on sub-maximal and maximal exercise performance. Med Sci Sports Exercise 1996;28:482-9.

5 Wexler P. Encyclopaedia of toxicology. St Louis: Academic Press, 1998.

6 Myerscough H. Herbal remedies: How much do we know? Aust Fam Physician 1998;27:1037-40.

7 Olin BR. Lawrence review of natural products, facts and comparisons. St Louis: Nov 1996.
8 Pepping J. Kava: Piper methysticum. Am J Health Syst Pharm 1999;56:957-60.

9 Munte TF, Heinze HJ, Matzke MA, et al. Effects of oxazepam and an extract of kava roots (Piper methysticum) on event-related potentials in a word recognition task. Neuropsychobiology 1993;27:46-53.

10 Tonks A. Treating generalised anxiety disorder. BMJ 2003;326:700-2.

11 Gunatilaka AAL, Arseculeratne SN, Panabokke RG, et al. Studies on medicinal plants of Sri Lanka. Planta Medica 1980;39:66-72.

12 Kanth VR, Diwan PV. Analgesic, antiinflammatory and hypoglycaemic activities of Sida cordifolia. Phytotherapy Research 1999;13:75-7.

13 Zahn KA, Raymod LL, Purssell RA. Cardiovascular toxicity after ingestion of "herbal ecstacy" J Emerg Med 1999; 17:289-91.

14 Foster S. Effect of lorazepam and haloperidol for rapid tranquilization in a psychiatric emergency room setting. International Journal of Clinical Psychopharmacology 1997; 12:175-9.

\title{
Gamma hydroxybutirate use for sexual assault
}

\author{
M Varela, S Nogué, M Orós, Ò Miró
}

Emerg Med J 2004;21:255-256. doi: 10.1136/emj.2002.002402

The use of gamma hydroxybutyrate (GHB) as a recreational drug has quickly spread among European young people during the past decade. Although it has been claimed that GHB can be potentially used to facilitate sexual assault, no case reports have been previously described. A case is described in which GHB was used with that criminal purpose and a review of previous literature is undertaken.

A n estimated $20 \%$ of adult women, $15 \%$ of college aged women, and $12 \%$ of adolescent girls have experienced sexual assault or sexual abuse. ${ }^{1}$ Drug facilitated sexual assault has increasingly occurred in the past few years, and gamma hydroxybutyrate (GHB), best known by the street name of "liquid ecstasy", has repeatedly been claimed as one of the most commonly used for this purpose. However, objective analytical data demonstrate that GHB is much more unusual than expected and that ethanol is by far the substance more frequently found (table 1). ${ }^{23}$ None the less, as nothing is reported in these studies about whether drugs were voluntarily consumed by the victim or intentionally used by the perpetrator to gain his/her control, the true role for each drug in sex crimes remains to be defined.

We report a case in which GHB use as sexual assault facilitator seems to be present and we also review previous literature.

\section{CASE REPORT}

A 20 year old woman presented herself to the emergency department suspecting that she had probably been sexually assaulted. The previous night she had been dancing in a discotheque, she had had two drinks and smoked cigarettes, but denied any illegal drug use. At this point, she had a gap in her memory. Her next memory was that she woke up in bed in a strange flat with two unknown men who took her to the street, left her, and disappeared.

She complained of mild proctalgia and vulvodynia. Her medical history was irrelevant. The patient had been sexually active from the age of 17. Physical examination was only remarkable for the presence of a recent haematoma on the inside of the right thigh. The external and internal genitalia, perineum, and anus were normal, and the hymen was broken and healed, and presence of spermatozoa in vaginal samples was confirmed by optic microscopy. Psychiatric evaluation uncovered no psychopathological data apart from a reactive depression.

The routine screening of the urine sample (enzyme immunoassay, ACA Star) for opioids, cocaine, cannabis, amphetamines, benzodiazepines, and ethanol was negative. A further determination of GHB by gas chromatography selected ion monitoring mass spectrometry (HP5971) was requested and confirmed as positive.

\section{DISCUSSION}

GHB was initially developed and used as an anaesthetic inductor, but its use in medicine progressively decreased because of its low analgesic properties and high incidence of secondary effects. Conversely, GHB recreational use rapidly spread to most developed countries during the past decade. ${ }^{4}$ In Catalonia, despite the fact that the first cases were described during 1999,5 more than 100 cases have been reported by a single institution only two years later. ${ }^{6}$ Users especially appreciate its euphoric, disinhibitory, sedative and anabolic effects and some people have also mentioned aphrodisiac properties. GHB is quickly and effectively absorbed in the stomach, achieves a blood peak in few minutes, easily reaches the central nervous system, and has a short half life (27 minutes), being expelled unchanged by the kidneys. GHB is not detectable in urine after 12 hours. ${ }^{2}$ The

Table 1 Substances identified in 3212 suspected cases of drug facilitated sexual assault ${ }^{3}$

\begin{tabular}{|c|c|}
\hline Number of drugs & $\begin{array}{l}\text { Number of cases } \\
\text { (\% of total cases) }\end{array}$ \\
\hline $\begin{array}{l}\text { None } \\
\text { One } \\
\text { More than one }\end{array}$ & $\begin{array}{l}1252(39) \\
1121(35) \\
839(26)\end{array}$ \\
\hline Kind of drug & $\begin{array}{l}\text { Number of cases } \\
\text { (\% of positive cases) }\end{array}$ \\
\hline $\begin{array}{l}\text { Ethanol } \\
\text { Cannabinoids } \\
\text { Benzodiazepines } \\
\text { Cocaine } \\
\text { Amphetamines } \\
\text { Opioids } \\
\text { Gamma hydroxybutyrate } \\
\text { Barbiturates }\end{array}$ & $\begin{array}{l}1272(76) \\
582(28) \\
372(18) \\
263(13) \\
191(9) \\
116(6) \\
105(5) \\
34(2)\end{array}$ \\
\hline
\end{tabular}


main clinical effect of GHB overdose is a decrease of consciousness, which is usually manifested about 15 minutes after oral administration and persists for about three hours on average. In up to $17 \%$ of patients arriving at the emergency department because of GHB overdose, a deep coma (Glasgow Consciousness Scale of 3 points) is present. ${ }^{6}$

Since GHB has been banned in most countries, consumers have increasingly changed the use of GHB by gamma butyrolactone and/or 1,4 butanediol. These industrial solvents are precursors of GHB and are comparatively easy to obtain. In fact, they can be brought via the internet. Although the relevance of this shift has not been studied in Catalonia, gamma butyrolactone and 1,4 butanediol is though to be the cause of a significant number of GHB overdoses in many parts of the world, specially in Australia and United States. ${ }^{7-11}$

The most typical street presentation of GHB is as a colourless and odourless liquid with a very slightly salty taste; GHB can therefore be mixed with drinks with no appreciable change in their organoleptic characteristics. This, together with the pharmacokinetic and pharmacodynamic properties referred to above, makes GHB ideal for drug facilitated sexual assaults, especially when it is considered that GHB also causes passivity, loss of will to resist, relaxation of voluntary muscles, and lasting anterograde amnesia concerning events occurring under the influence of the drug. However, no individual case reports have been reported confirming this hypothesis to date. It is possible that analytical difficulties surrounding GHB determination (especially the necessity of a targeted analysis for detection because of GHB is not routinely included in current toxicological drug abuse screenings) is contributing to the lack of data regarding this issue.

The symptoms manifested by the patient in this case report are consistent with the known pharmacological effects of GHB. GHB has been shown to act synergistically with other central nervous system depressants such as ethanol. Symptoms may also mimic those of alcohol and not all patients are screened for GHB. For all these reasons we want to emphasise the importance of GHB (and precursors) being considered with any causes of sexual assault, and should be included with any drugs of abuse screen that is done in these cases.

\section{Authors' affiliations}

M Varela, O Miró, Emergency Department, Hospital Clínic, Barcelona, Spain

S Nogué, Toxicology Unit, Hospital Clínic, Barcelona

M Orós, Forensic Department, Barcelona

Correspondence to: Dr Ò Miró, Emergency Department, Hospital Clínic, Villarroel 170, 08036 Barcelona, Catalonia, Spain; omiro@clinic.ub.es

Accepted for publication 17 January 2003

\section{REFERENCES}

1 Council on Scientific Affairs, American Medical Association. Violence against women: relevance for medical practitioners. JAMA 1992;267:3184-9.

2 Elsohly MA, Salamone SJ. Prevalence of drugs used in cases of alleged sexual assault. J Anal Toxicol 1999;23:141-6.

3 Slaughter L. Involvement of drugs in sexual assault. J Reprod Med 2000;45:425-30.

4 Chin RL, Sporer KA, Cullison B, et al. Clinical course of gammahydroxybutyrate overdose. Ann Emerg Med 1998;31:729-36.

5 Espinosa G, Miró $O$, Nogué $S$, et al. Intoxicación por extasis líquido: estudio de 22 casos. Med Clin (Barc) 2001;117:56-8.

6 Miró O, Nogué S, Espinosa G, et al. Trends in illicit drug emergencies: the emerging role of gamma-hydroxybutyrate. J Toxicol Clin Toxicol 2002;40:129-35

7 Zvosec DL, Smith SW, McCutcheon JR, et al. Adverse events, including death, associated with the use of 1,4-butanediol. N Engl J Med 2001;344:87-94.

8 Mason PE, Kerns WP. Gamma-hydroxybutyric acid (GHB) intoxication. Acad Emerg Med 2002;9:730-9.

9 Schwartz RH, Milteer R, Le Bean MA. Drug-facilitated sexual assault ("date rape ${ }^{\prime \prime}$ ). South Med J 2000;93:558-61.

10 Smith KM, Larive LL, Romanelli F. Club drugs: methyl-enedioxymethamphetamine, flunitrazepam, ketamine hydrochloride, and gammahydroxybutyrate. Am J Health Syst Pharm 2002;59:1067-76.

11 Caldicott DG, Kuhn M. Gamma-hydroxybutyrate overdose and physostigmine: teaching new tricks to an old drug? Ann Emerg Med 2001;37:99-102. 


\title{
Ultrasound by emergency physicians to detect abdominal aortic aneurysms: a UK case series
}

\author{
A Walker, J Brenchley, J P Sloan, M Lalanda, H Venables
}

Emerg Med J 2004;21:257-259. doi: 10.1136/emj.2002.002121

Early identification of abdominal aortic aneurysms in some patients can be difficult and the diagnosis is missed in up to $30 \%$ of patients. Ultrasound cannot be used to identify a leak, but the presence of an aneurysm in an unstable patient is conclusive. With minimal training emergency physicians can easily identify the aorta and thus in the early phase of resuscitation an aneurysm can be confidently excluded. The purpose of the examination is not to delineate the extent of the aneurysm, but to identify those patients that will need emergency surgery. A series of patients presented to the department in an unstable condition with equivocal abdominal signs. An ultrasound scan in the resuscitation room by members of the emergency department revealed an aneurysm, which was enough to convince the vascular surgeons to take the patient straight to theatre with good results. In patients who are stable, computed tomography will continue to be used to evaluate the extent of the aneurysm and identify a leak.

A bdominal aortic aneurysms (AAA) present an important diagnostic challenge to emergency physicians. Although not a common condition, they are associated with significant mortality and early diagnosis is essential.

The diagnosis may be difficult in the emergency situation as patients may present with a non-specific history, and staff need a high index of suspicion to consider AAA in the differential diagnosis. ${ }^{1}$ Computed tomography is the gold standard investigation but can lead to a delay in definitive diagnosis and treatment (especially out of normal working hours), and transfer to scan may be associated with further risks or deterioration. An early ultrasound scan in the resuscitation phase may be the primary investigation of choice.

Some departments have protocols whereby patients who are suspected of having a AAA are transferred directly to a vascular surgery centre for definitive diagnosis and treatment.

This may entail inappropriate patients being transferred, or delays at the presenting hospital if inexperienced medical staff require senior backup to make this decision.

Ultrasonography is routinely used for screening and monitoring of aneurysm diameter ${ }^{2}$ and a limited ultrasound scan can reliably record the presence of an AAA.

If a normal aorta is clearly seen (as in most cases) an aneurysm can be confidently excluded. In the emergency setting no attempt is made to define the limits or relations of the aneurysm.

Ultrasound is not accurate in determining the presence of a leak from the aneurysm. In one study in emergency department patients, sonography was accurate in demonstrating presence or absence of aneurysm (98\%), but its sensitivity for extraluminal blood was poor $(4 \%){ }^{3}$
The combination of an aneurysm on ultrasound and an unstable patient is enough to warrant an emergency vascular surgery opinion.

\section{PRINCIPLES OF EMERGENCY ULTRASOUND}

Ultrasound use by emergency physicians is a focused examination to answer a single clinical question. In the assessment of trauma patients the purpose of the FAST (focused assessment with sonography in trauma) scan is to identify (rule in) the presence of free intraperitoneal fluid. In the context of trauma, this is assumed to be blood. Further management decisions are made according to the patient's condition, but ultrasound adds valuable information in the early stages of assessment.

\section{TRAINING}

All middle grade and senior emergency physicians at Leeds General Infirmary had previously been trained to use ultrasound in the evaluation of blunt abdominal trauma (FAST). This entailed two sessions of both didactic training on the principles of ultrasound and the FAST protocol, and practical experience on normal volunteers and simulated patients (peritoneal dialysis patient volunteers). Emergency physicians were then required to record scans on 10 normal volunteers, these were reviewed by expert sonographers before accreditation as an emergency physician sonographer.

Data from all scanned patients are routinely recorded and suggest that there is little skill attrition with time. Rotational middle grade staff have been trained in the technique and on return to the department months later continue to exhibit adequate sonography skills.

Trained emergency physician sonographers underwent a further session of training by expert sonographers. This included a review of aortic anatomy, demonstrations of normal ultrasound appearances, and review of AAA ultrasound appearance. Once trained, the emergency AAA scan could be performed in less than five minutes. The appearances of the normal aorta scan view are shown in figure 1.

\section{CASE SERIES}

We present a series of patients who have attended our emergency department over a six month period and had a provisional diagnosis of AAA.

All patients underwent an ultrasound scan performed by emergency physicians, and after discussion with the vascular surgeons were immediately transferred to theatre.

\section{Case 1}

A 65 year old man bent down to lift a box and felt pain in his left hip. On presentation to hospital, he was

Abbreviations: AAA, abdominal aortic aneurysms; FAST, focused assessment with sonography in trauma 


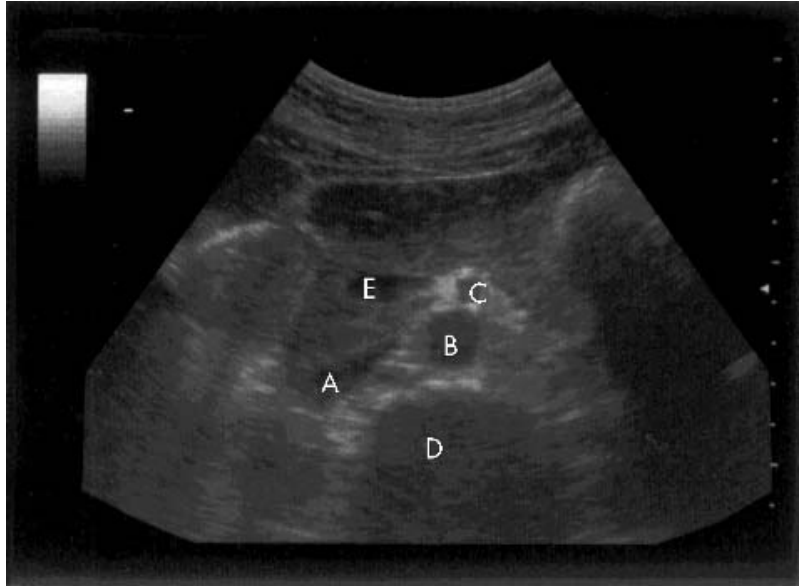

Figure 1 Normal anatomy (transverse). A, IVC; B, aorta; C, superior mesenteric artery; $D$, vertebral body; $E$, portal vein.

haemodynamically stable with a palpable AAA, confirmed on ultrasound. Shortly thereafter he became cardiovascularly unstable and was transferred to theatre for repair of an infrarenal AAA. He made a good recovery and was well six months later.

\section{Case 2}

A 72 year old man presented with abdominal and back pain. While in the emergency department he collapsed and the ultrasound scan in the resuscitation room demonstrated a $7 \mathrm{~cm}$ aneurysm. He was transferred to the operating theatre for repair and was well three months later.

\section{Case 3 (fig 2)}

A 69 year old man collapsed with abdominal pain and was brought to the emergency department. An ultrasound scan in the resuscitation room revealed a large AAA. He was transferred to operating theatre and is alive and well one year later.

\section{Case 4}

A 67 year old man had experienced abdominal and back pain overnight, in association with diarrhoea. He was hypotensive on arrival and a $7 \mathrm{~cm}$ AAA was discovered when an emergency physician performed ultrasound in the resuscitation room. He was transferred to the operating theatre and survived the repair but died three days after operation.

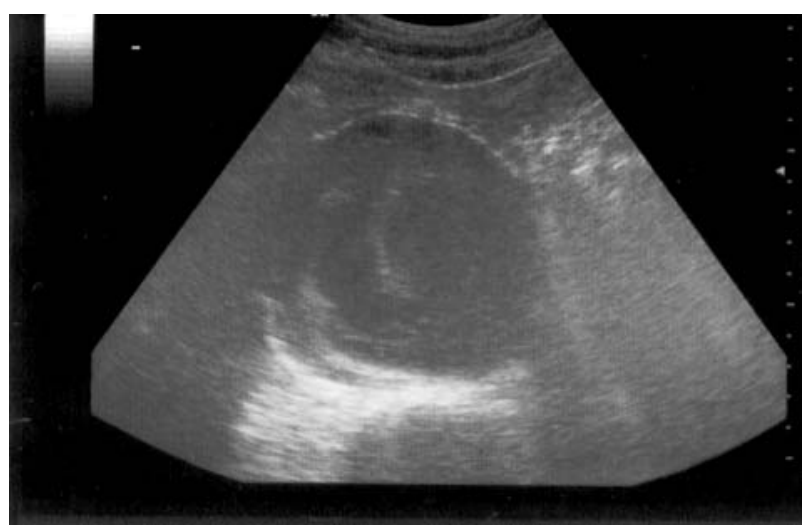

Figure 2 Case 2, $7 \mathrm{~cm} \mathrm{AAA.}$

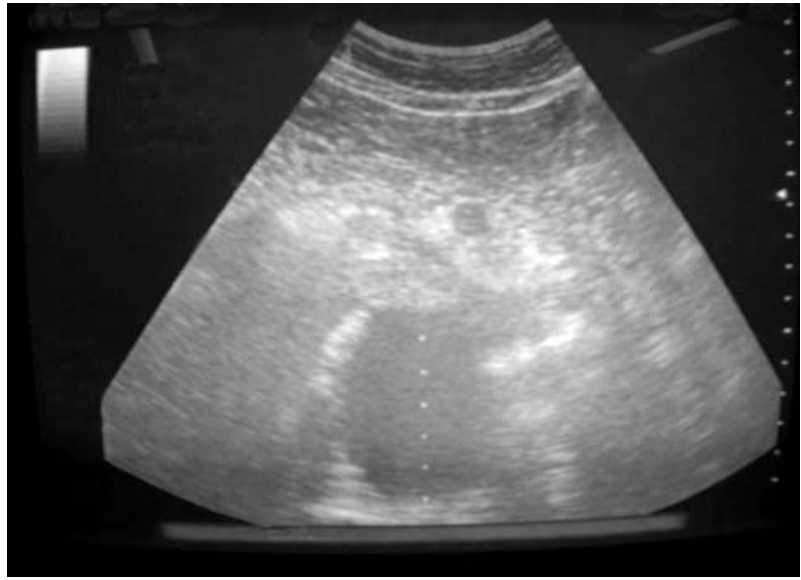

Figure 3 Case 5, $6 \mathrm{~cm}$ AAA.

\section{Case 5 (fig 3)}

A 58 year old man had colicky abdominal pain radiating to his back. He was haemodynamically stable and had an ultrasound scan performed as routine and to increase SHO awareness of the investigation. A $6 \mathrm{~cm}$ AAA was detected and he was referred for review by the vascular surgeons. Thirty minutes later he had a sudden haemodynamic collapse and was resuscitated and transferred straight to theatre.

These cases demonstrate the effectiveness of an emergency physician ultrasound scan in appropriate patients. Ultrasound has also been used successfully to exclude an AAA in hypotensive patients seen in the resuscitation room, and has therefore directed further investigations more appropriately. This is a small case series only looking at patients with positive scans. There is more work to be done evaluating the technique as rule out tool in these circumstances.

\section{DISCUSSION}

Some patients have a clear history and obvious clinical signs of an AAA. In these the diagnosis is not difficult. It has been clearly established that early diagnosis and surgery has significant survival benefits in these patients. An emergency physician performed ultrasound scan in the resuscitation room can be completed early while resuscitation is ongoing. Use of ultrasound by emergency physicians to exclude an AAA, is common in other countries. ${ }^{4}$

As increasing numbers of patients are transferred to a tertiary centre for surgery after acute presentation. A timely emergency physician performed ultrasound scan may expedite the decision to transfer.

Studies have shown that emergency physicians are accurate in the diagnosis of AAA on ultrasound. One study from Australia included patients in whom the diagnosis of AAA was suspected. ${ }^{5}$ Sixty eight scans were performed; 26 scans were positive, 40 scans yielded negative findings, and 2 scans were indeterminate. Scan interpretations were 100\% accurate, compared with standard imaging or radiology review of the emergency ultrasound scan. In this study the primary benefit of ultrasonography was to exclude the diagnosis, but positive scans provided significant benefits for patients with AAA and led to improved management plans.

In our department, the use of ultrasound for AAA diagnosis followed naturally once the machine had been purchased by the department and emergency department staff had been trained in the FAST technique. The presence of an external aortic diameter of greater than $3 \mathrm{~cm}$ is considered 
diagnostic of an AAA, although increasing size increases the risk of rupture.

Initially there were concerns voiced by radiology colleagues about the use of ultrasound by non-radiologists. Most vascular surgeons however, are familiar with the ultrasound appearances of AAA, and a consensus decision on further management was reached in the cases presented. In patients with leaking AAAs, the speed of transfer to definitive care is a significant prognostic factor, rapid access to a senior vascular surgical opinion may be expedited by the emergency physician ultrasound scan.

We have shown that ultrasound skills for specific limited indications are easily learnt and retained. Support of the local radiology department is invaluable in introducing ultrasound into the emergency department. In our department all scans were initially reviewed by expert sonographers and although there was some disagreement about scan quality, none of the clinical conclusions drawn was invalid. Hard copies of all scans were obtained for inclusion in the patient's notes and audit purposes. Ongoing review of a proportion of scans is worthwhile to monitor quality, this could be performed by an experienced emergency physician sonographer or radiology colleagues.

\section{CONCLUSIONS}

A limited ultrasound scan is a rapid screening test for detection of AAA in the resuscitation room. Emergency physicians competent in other ultrasound techniques can reliably perform the technique after a short training programme

\section{Authors' affiliations}

A Walker, J P Sloan, M Lalanda, Department of Emergency Medicine, Leeds General Infirmary, Leeds, UK

J Brenchley, Department of Emergency Medicine, Barnsley District General Hospital, Barnsley, UK

H Venables, School of Healthcare Studies, University of Leeds, Leeds, UK

Correspondence to: Dr J Brenchley, Department of Emergency Medicine, Barnsley District General Hospital, Gawber Road, Barnsley S75 2EP, UK; jane.brenchley@bdgh-tr.trent.nhs.uk

Accepted for publication 7 March 2003

\section{REFERENCES}

1 Miller J, Miller J. Small ruptured abdominal aneurysm diagnosed by emergency physician ultrasound. Am J Emerg Med 1999;17:174-5.

2 Shuman WP, Hastrup W, Kohler TR, et al. Suspected leaking abdominal aortic aneurysm: use of sonography in the emergency room. Radiology 1988; 168:117-19.

3 Goldberg BB. Aortosonography. Int Surg 1977;62:294-7.

4 Stahmer SA. Accident and emergency medicine. BMJ 1988;316:1071-4.

5 Kuhn M, Bonnin RL, Davey MJ, et al. Emergency department ultrasound

scanning for abdominal aortic aneurysm: accessible, accurate, and advantageous. Ann Emerg Med 2000;36:219-23.

\section{Bone marrow toxicity after yellow phosphorus ingestion}

\section{A J Tafur, J A Zapatier, L A Idrovo, J W Oliveros, J C Garces}

Suicidal ingestions of fireworks containing yellow phosphorus occur often during holidays. A case is reported of a 17 year old woman who intentionally ingested an estimated amount of $5.5 \mathrm{mg}$ of yellow phosphorus, presenting with upper abdominal pain as the only complaint, a physical examination was normal. Blood tests showed a considerable decrease in the granulocyte count; the bone marrow biopsy revealed a decreased cellular mass with degenerative changes. Spontaneous remission was observed during the next 48 hours, with no further complaints.

$\mathrm{S}$ uicidal ingestions of round, penny sized fireworks known as diablillos are popular especially during the period of Christmas holiday. Each diablillo usually weighs $310 \mathrm{mg}$ containing $2.4 \%$ of yellow phosphorus (YP), $39.4 \%$ of silica, and $50 \%$ of potassium chlorate. ${ }^{1}$ The estimated lethal dose of YP is $1 \mathrm{mg} / \mathrm{kg} .^{2}$ We present a case in which the ingestion of firework containing YP induced reversible bone marrow toxicity verified on biopsy examination.

\section{CASE REPORT}

A 17 year old woman, weighing $50 \mathrm{~kg}$, was admitted to the emergency room after the intentional ingestion of three quarters of a diablillo nine hours before arrival (about $5.5 \mathrm{mg}$ of YP). Her vital signs were stable and the patient was conscious and well oriented. The chief complaint was upper abdominal pain and the rest of the physical examination was normal. There was no history of previous relevant illness. Gastric lavage was started with a solution containing potassium permanganate 1:1000; followed by activated charcoal and a mineral cathartic. Blood samples were obtained, and the analysis reported white blood cell (WBC) count $6.400 / \mu \mathrm{l}$, red blood cell (RBC) count $3.9 \times 10^{6} / \mu \mathrm{l}$, haemoglobin (Hb)120 g/l, and platelet count $258000 / \mu \mathrm{l}$. Granulocyte count was 5900/ $\mu$ l. Hepatic and renal functions, as well as electrolytes were all normal. Intravenous fluids, and folic acid with iron supplementation were prescribed as support treatment.

After 24 hours in hospital, blood tests were repeated

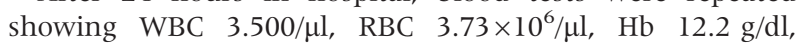
platelet count $226.000 / \mu \mathrm{l}$, and granulocytes decreased to $900 / \mu \mathrm{l}$. A bone marrow biopsy was undertaken, and the histopathological analysis reported intense interstitial oedema, haemorrhages, and some necrotic foci. The morphology of the three cellular lines was normal, but the total cellular mass was at $50 \%$. Neoplasic or fibrotic changes were not found; suggesting the diagnosis of unspecified degenerative toxic changes in the bone marrow (fig 1).

The patient remained stable and no complications appeared during her stay in hospital. Spontaneous resolution of the neutropenia was observed during the next 48 hours. The patient was discharged, and returned one month later for follow up presenting no further complains. 


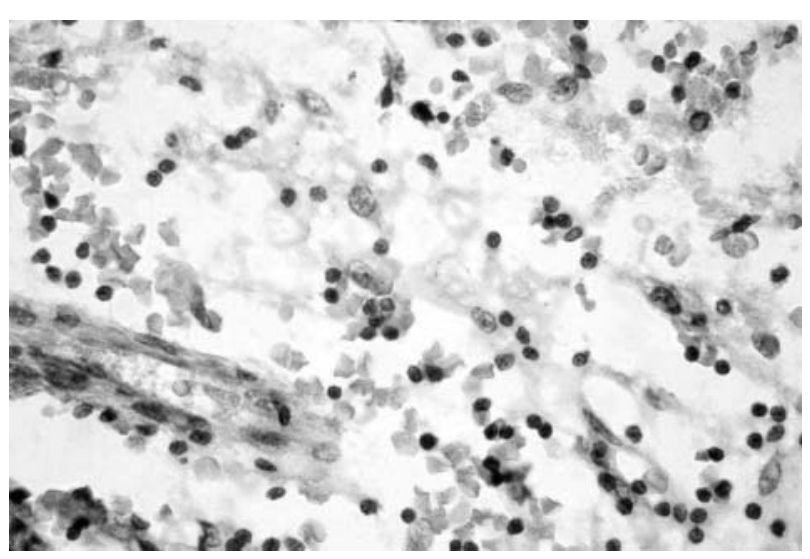

Figure 1 Bone marrow biopsy showing interstitial oedema, haemorrhages, and necrotic foci. The morphology of the three cellular lines is preserved. The total cellular mass is at about $50 \%$.

\section{DISCUSSION}

At the beginning of industrialisation, the long term exposure with air contaminated with YP particles and dermal contact were the most common ways of intoxication. Now, self induced YP intoxication remains an important health problem and is related to a significant mortality. ${ }^{3}$

YP is rapidly absorbed through the intestinal tract and a few hours after the ingestion $69 \%$ to $73 \%$ of the total ingested dose concentrates into the liver where severe complications develop. ${ }^{4}$ Also smaller concentrations reach the brain, striated muscle, and the kidneys. The short term effects of YP intoxication include gastrointestinal symptoms, liver changes, renal failure, arrhythmias, seizures, coma, and cardiovascular collapse. ${ }^{5}$

Published data recommend that decontamination is started within two to five hours after ingestion. ${ }^{6-9}$ Decontamination procedures in our centre within the first 12 hours after ingestion are based upon high incidence of YP poisoning, and death rates. The decision about what solution should be first during gastric lavage remains undetermined. ${ }^{36}$ We prefer to start preventing further absorption with a substance that oxidised phosphorus.

Reports of haematological disturbances after the exposure with YP are scarce. ${ }^{10}{ }^{11}$ Experimentally, YP produces a significant increase in the leucocyte count and in some cases intense erythrocyte destruction, as seen with chickens and rabbits. In humans, the effects of YP intoxication present as a temporary proliferation of the red blood cells, without a simultaneous increase in the haemoglobin titre, and a decrease in the leucocyte count. ${ }^{12}$ Our patient had a considerable decrease in the granulocyte count measured 24 hours after the admittance. This fact prompted us to perform the bone marrow biopsy. Also, a mild decrease of leucocytes, erythrocytes, and platelets, with haemoglobin titres that remained normal, was recorded.

In vitro, elemental phosphorus induces a reduction in the cellular replication rate, as the phosphorus concentration increases, arresting cells in the metaphase stage of mitosis instead of destroying them. ${ }^{13}$ Histopathological examination of the biopsy samples revealed unspecified bone marrow changes with normal cells and a decreased cellular mass, showing that this phenomenon may occur also in the human bone marrow. These data suggest the possibility of a direct toxic effect of YP in the bone marrow.

The reported mortality after YP intoxication varies from $23 \%$ to $73 \%$, and it is directly related with the ingested dose. ${ }^{3}$ The good outcome of our patient could be explained on the basis of the ingested small amount of diablillo (5.5 mg of YP). Most of the reported deaths were attributable to hepatic complications or cardiovascular collapse; but none to secondary to haematological abnormalities. It is important to emphasise that histopathology of the bone marrow in these critically ill patients was not studied.

\section{Authors' affiliations \\ A J Tafur, J A Zapatier, L A Idrovo, Toxicology Service, Luis Vernaza Hospital, Guayaquil, Ecuador \\ J W Oliveros, J C Garces, Department of Internal Medicine, Section \\ "Santa Elena", Luis Vernaza Hospital}

Correspondence to: Dr J A Zapatier, Toxicology Service, Luis Vernaza Hospital, Guayaquil, PO Box 3615, Ecuador; jzapatier@hotmail.com

Accepted for publication 8 August 2003

\section{REFERENCES}

1 Marin GA, Montoya CA, Sierra JL, et al. Evaluation of corticosteroid and exchange-transfusion treatment of acute yellow phosphorus intoxication. N Engl J Med 1971;284:125-8.

2 Fernandez OU, Canizarez LL. Acute hepatotoxicity from ingestion of yellow phosphorus-containing fireworks. J Clin Gastroenterol 1995;21:139-42.

3 McCarron MM, Gaddis GP, Trotter AT. Acute yellow phosphorus poisoning from pesticide pastes. Clin Toxicol 1981;18:693-712.

4 Ghoshal AK, Porta EA, Hartroft WS. Isotopic studies on the absorption and tissue distribution of white phosphorus in rats. Exp Mol Pathol 1971;14:212-19.

5 Desai H. Hazardous material toxicology. In: Sullivan JB, Krieger GR, eds. Principles of environmental health. Baltimore, MD: Williams and Wilkins, 1992:937-9.

6 Krenzelok E, Vale A. Position statements: gut decontamination. American Academy of Clinical Toxicology; European Association of Poisons Centres and Clinical Toxicologists. J Toxicol Clin Toxicol 1997;35:695-786.

7 Chyka PA, Seger D. Position statement: single-dose activated charcoal. American Academy of Clinical Toxicology; European Association of Poisons Centres and Clinical Toxicologists. J Toxicol Clin Toxicol 1997;35:721-41.

8 Barceloux D, McGuigan M, Hartigan-Go K. Position statement: cathartics. American Academy of Clinical Toxicology; European Association of Poisons Centres and Clinical Toxicologists. J Toxicol Clin Toxicol 1997;35:743-52.

9 Tenenbein M. Position statement: whole bowel irrigation. American Academy of Clinical Toxicology; European Association of Poisons Centres and Clinical Toxicologists. J Toxicol Clin Toxicol 1997;35:753-62.

10 Newburger RA, Beaser SB. Phosphorus poisoning with recovery accompained by electrocardiographic changes. Am J Med 1948;4:927-30.

11 Beloskurskaia GI, Balmakhaeva RM. Functional and morphologic characteristics of leukocytes in patients with chronic phosphorus poisoning. Gigiena truda i professional'nye zabolevaniia 1982;9:46-9.

12 Taussie O. Blood count results in cases of acute phosphorus intoxication. Archives fur Experimentelle Pathologie und Pharmakologie 1992;30:161-79.

13 Li MF, Traxler GS, Langille LM. Toxic effects of elemental phosphorus on L-cells cultivated suspension. Canadian Journal of Zoology 1970;48:133-8. 


\title{
Late presenting congenital diaphragmatic hernia
}

\author{
A V Sridhar, S Nichani
}

Emerg Med J 2004;21:261-262. doi: 10.1136/emj.2003.007435

\begin{abstract}
Delayed herniation of the abdominal contents through a congenital diaphragmatic hernia may occur beyond the neonatal period. The case is reported of a 9 month old child presenting with acute respiratory distress secondary to tension gastrothorax. The chest radiograph showed a tension gastrothorax. Nasogastric tube placement confirmed herniation of the stomach into the left chest and is the initial treatment of choice when a tension gastrothorax is identified. The late presenting congenital diaphragmatic hernia poses considerable diagnostic challenges often leading to misdiagnosis and risk of thoracocentesis. The possibility of late presenting congenital diaphragmatic hernia should be considered in unusual cases of pneumothorax, especially in the absence of trauma so that unnecessary procedures like chest tube drainage can be avoided.
\end{abstract}

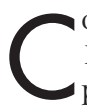
ongenital diaphragmatic hernia $(\mathrm{CDH})$ occurs in about 1 in 3000 births. The most common defect is the posterolateral (Bochdalek) type. Over $90 \%$ of the patients will be diagnosed either antenatally or will present with respiratory distress in the first few hours of life. In these cases there are few diagnostic problems. There is a significant mortality associated with this group. ${ }^{1}$

However, about $5 \%$ to $30 \%$ of diaphragmatic hernias present beyond the neonatal period. ${ }^{2}$ Although the mortality in this group is low, the morbidity may be significant. The late presenting congenital diaphragmatic hernia poses considerable diagnostic challenges because of its varied presentation often resulting in diagnostic delay, inappropriate treatment, and potential fatal outcome. ${ }^{3}$

\section{CASE REPORT}

A previously healthy 9 month old boy presented to his local accident and emergency department with acute onset of breathlessness, grunting, and excessive screaming of one to two hours' duration. There was no history of trauma or any previous respiratory or gastrointestinal illness.

On examination he was afebrile, poorly perfused, tachycardic, tachypnoeic with moderate subcostal and intercostal recession. Air entry was reduced on the left side chest with mediastinal shift to the right. Abdominal examination was normal. He needed high flow oxygen to maintain oxygen saturation and fluid resuscitation with intravenous $0.9 \%$ saline.

A chest radiograph (fig 1) showed a massive gastrothorax on the left side with mediastinal shift to the right side. This was confirmed by placing a nasogastric tube in the stomach (fig 2), which also gave symptomatic relief to the patient. Computed tomography of the chest (fig 3) demonstrated left sided Bochdalek diaphragmatic hernia with pronounced herniation of the stomach and proximal small bowel into the left hemithorax, with contralateral mediastinal shift and complete collapse of the left lung.
He was ventilated and transferred to the paediatric intensive care unit. On laparotomy there was a small posterolateral (Bochdalek) defect in the left hemidiaphragm with the stomach, proximal small bowel and spleen in the left hemithorax that were reduced and the diaphragm was repaired. He also had malrotation of the gut for which he underwent a Ladd's procedure. Postoperative chest radiograph showed full expansion of the left lung, and the patient made a full recovery.

\section{DISCUSSION}

In late presenting congenital diaphragmatic hernias, the extent of herniation of abdominal viscera into the thorax may vary, leading to acute or intermittent symptoms. A previously normal chest radiograph has been reported in number of cases suggesting that in such cases the defect is long standing, but the viscera are confined by the hernial sac or obturated by a solid organ. The patient becomes symptomatic when actual herniation takes place later in life because of rupture of the hernial sac. There is probably a second group of patients in whom the herniation has been long standing, but who only present when a complication of the herniated contents such as volvulus or strangulation occurs. ${ }^{3}$

Berman et al in their series of 26 patients with late presenting $\mathrm{CDH}$, reported that 16 patients had a initial diagnosis of primary lung abnormality, with four patients undergoing thoracocentesis. ${ }^{3}$ There are a number of case reports in the literature where late presenting diaphragmatic hernias have been misdiagnosed as pneumothorax and patients have undergone unnecessary emergency thoracocentesis. ${ }^{4-6}$ In our patient although the clinical presentation was suggestive of left sided pneumothorax, a differential diagnosis of left sided congenital diaphragmatic hernia was

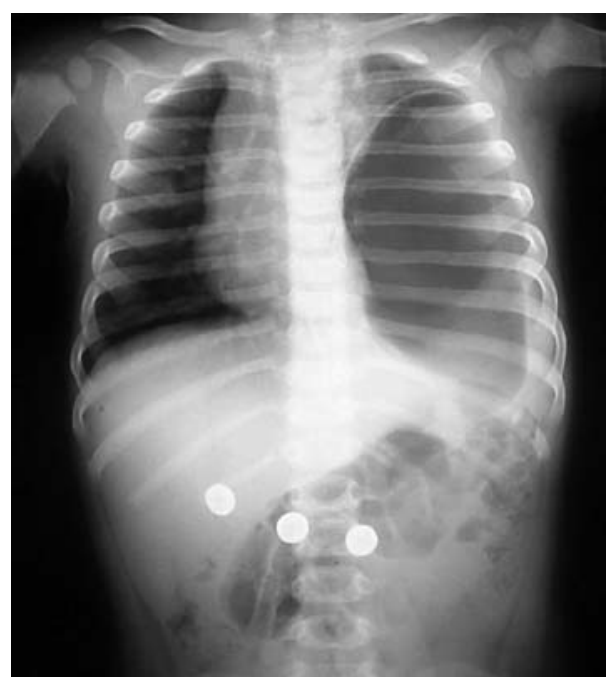

Figure 1 Chest radiograph showing massive gastrothorax on the left side of the chest with mediastinal shift to the right. 


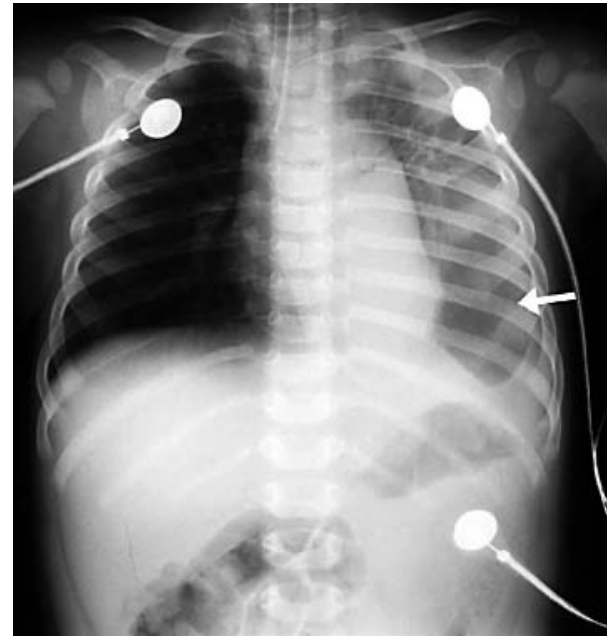

Figure 2 Chest radiograph showing the stomach with the nasogastric tube (arrow) on the left side of the chest.

considered and confirmed by chest radiograph after nasogastric tube insertion, which not only showed the stomach on the left side of the thorax, but also relieved his respiratory symptoms.

The inappropriate insertion of a chest drain, although relieving the symptoms temporarily, may result in serious consequences by damaging intrathoracic abdominal viscera. There is also the risk of spillage of the gastric or intestinal contents into the thoracic cavity leading to mediastinitis. Damage to the spleen or blood vessels in cases of left sided $\mathrm{CDH}$ could result in life threatening haemorrhage. In cases of right sided $\mathrm{CDH}$, an intrathoracic liver may be damaged by a chest drain. ${ }^{6}$

If the diagnosis of late presenting $\mathrm{CDH}$ is suspected, an ultrasound is a useful diagnostic tool. ${ }^{7}$ When gastrothorax is suspected, a chest radiograph with a nasogastric tube in place will lead to the correct diagnosis. ${ }^{3}$ The other diagnostic tools available for the accurate diagnosis of late presenting $\mathrm{CDH}$ include computed tomography, magnetic resonance imaging, and upper or lower gastrointestinal contrast studies. ${ }^{7}$

In conclusion, the diagnostic possibility of late presenting congenital diaphragmatic hernia should be considered in unusual cases of pneumothorax, especially in the absence of trauma so that thoracocentesis can be avoided. Nasogastric

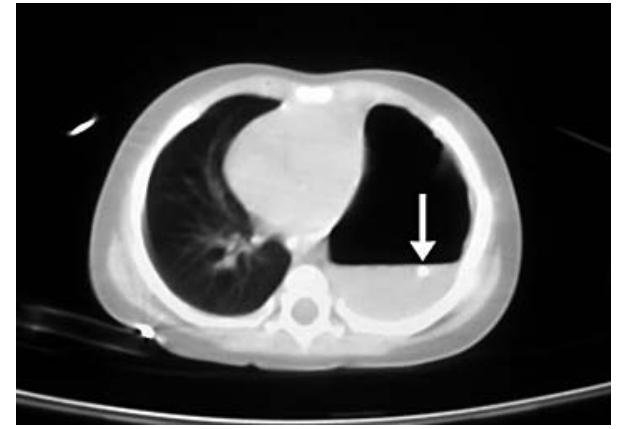

Figure $3 \mathrm{CT}$ scan at midthoracic level showing the herniation of the stomach into the left hemithorax with nasogastric tube (arrow) and collapse of the left lung.

tube placement must be considered as an early diagnostic or therapeutic intervention when the diagnosis is suspected. A high index of suspicion is required to avoid undue delay in diagnosis and inappropriate management.

\section{Authors' affiliations}

A V Sridhar, S Nichani, Paediatric Intensive Care Unit, Leicester Royal Infirmary, University Hospital of Leicester NHS Trust, Leicester, UK

Correspondence to: Dr A V Sridhar, Department of Child Health, Robert Kilpatrick Clinical Sciences Building, Leicester Royal Infirmary, Leicester LE2 7LX, UK; srinaidu@aol.com

Accepted for publication 5 June 2003

\section{REFERENCES}

1 Davenport M, Holmes K. Current management of congenital diaphragmatic hernia. Br J Hosp Med 1995;53:95-101.

2 Gleeson F, Spitz L. Piffalls in the diagnosis of congenital diaphragmatic hernia. Arch Dis Child 1991;66:670-1.

3 Berman L, Stringer D, Ein SH, et al. The late presenting paediatric Bochdalek hernia: a 20- year review. J Pediatr Surg 1988;23:735-9.

4 Fein JA, Loiselle J, Eberlein S, et al. Diaphragmatic hernia masquerading as pneumothorax in two toddlers. Ann Emerg Med 1993;22:1221-4.

5 Snyder HS, Salo DF, Kelly PH. Congenital diaphragmatic hernia presenting as massive gastrothorax. Ann Emerg Med 1990;19:562-4.

6 Coren ME, Rosenthal M, Bush A. Congenital diaphragmatic hernia misdiagnosed as tension pneumothorax. Pediatr Pulmonol 1997;24:119-21.

7 Oh KS, Newman B, Bender TM, et al. Radiological evaluation of the diaphragm. Radiol Clin North Am 1988;26:355-64. 


\section{"Minding the ends": a simple technique for repair of lower eyelid lacerations}

\section{S N Ali, P G Budny}

$\mathrm{t}$ is a common observation in suturing lower eyelid wounds that the cut ends of sutures cause a nuisance. When cut short they tend to irritate the cornea. Cut long they need to be controlled, but tape dressings often become detached because of epiphora or ointment application, as well as being a nuisance to replace.

There are many different methods of repair described in the literature $e^{1-3}$ but there are no accounts of any technique

A

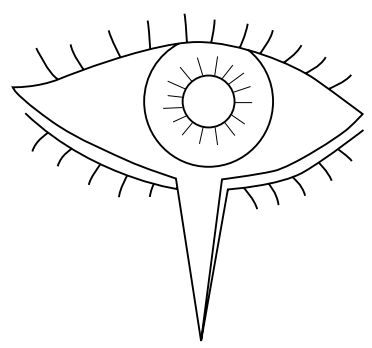

B

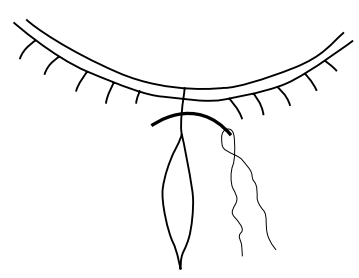

C

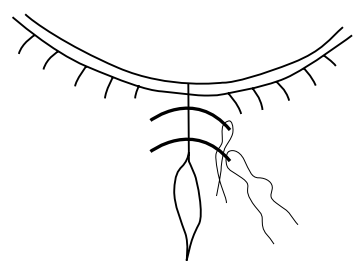

D

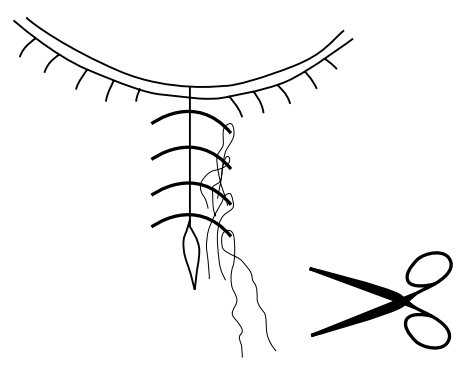

describing helpful management of suture ends. The technique we use is both simple and effective and can aid in suture removal as well. Starting from the tarsal end of the laceration, the suture ends are cut long (about $1 \mathrm{~cm}$ ) (fig 1A). When the next suture is tied the ends of the first one is taken into the loop and thus kept in place (fig $1 \mathrm{~B}$ ). Similarly with the next suture, the ends of the suture above it are held down (fig 1C). Every stitch in turn holds the cut edges of a stitch or two above it. It is important in placing the ends to avoid them being incorporated in the wound margin. Suture removal is started from the bottom end (fig lD). With removal of each stitch the ends of one above it are freed for easy control.

\section{Authors' affiliations}

S N Ali, P G Budny, Department of Plastic Surgery, Stoke Mandeville Hospital, Aylesbury, Buckinghamshire, UK

Correspondence to: Mr S N Ali, Department of Plastic Surgery, Stoke Mandeville Hospital, Aylesbury, Buckinghamshire HP21 8AL, UK; mrnadir@hotmail.com

Accepted for publication 16 May 2003

\section{REFERENCES}

1 Spaeth EB. The closure of vertical lid lacerations and the repair of vertical lid cicatrices. Am J Ophthalmol 1966;61:490-7.

2 Devoto MH, Kersten RC, Teske SA, et al. Simplified technique for eyelid margin repair. Arch Ophthalmol 1997;115:566-7.

3 Mehta HK. Primary repair of eyelid lacerations. Trans Ophthalmol Soc UK 1978;98:75-80.

Figure 1 Schematic view of the technique. 


\title{
Hidden shrapnel injury
}

\author{
J McKenzie, E Tiernan
}

Emerg Med J 2004;21:264-265. doi: 10.1136/emj.2003.007104

$\mathrm{t}$ has been stated that a "missed tertiary survey is a missed injury". ${ }^{1}$ A missed injury is especially likely when a patient's life threatening injuries and imminent transfer are a distraction to the attending doctors.

We hope this case reinforces the importance of a thorough head to toe examination despite distractions.

\section{CASE REPORT}

A middle aged civilian worker with the Ministry of Defence was testing an air driven projectile launcher. A technical error led to an explosion of the gas cylinder causing widespread

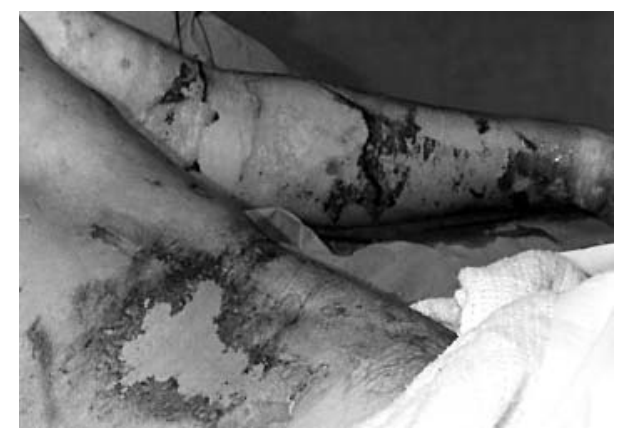

Figure 1 Widespread partial thickness burns disguising a penetrating left forearm wound.
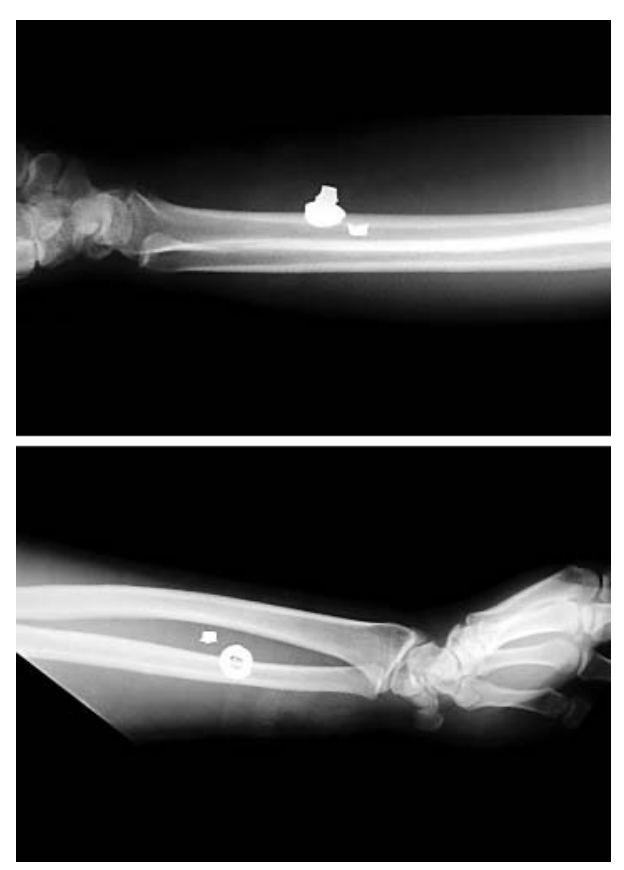

Figure 2 Radiographs of the left forearm showing shrapnel.

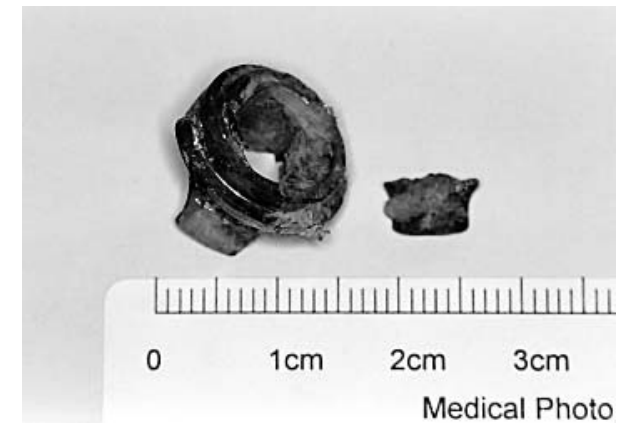

Figure 3 Shrapnel pieces after removal.

(about 25\%) mixed thickness burns to the patient's face, torso, both arms, and right hand.

The patient was first seen in a local accident and emergency department and given first aid. Transfer was arranged to a regional burns unit, but this was delayed because of the risk of inhalational injury. No radiographs were taken on admission to the district general hospital and there was no recorded secondary survey. On admission to the burns unit his main complaint was the deep burn to his right hand. A small wound on his left forearm, disguised in a dermal burn, was not thought significant (fig l). It was not until he was scheduled for surgery, five days after admission to the burns unit, that a radiograph of his left arm revealed a large piece of shrapnel embedded in his forearm (fig 2). The only clue was increasing discomfort in the left forearm.

No neurovascular or tendon injury was noted preoperatively. The metal fragments extracted (fig 3) were located very close to the median nerve. The area needed debriding as there was necrotic tissue. After delayed closure there was some transient cutaneous sensory deficit at the wrist, in the distribution of the medial antebrachial cutaneous nerve.

The burns were treated with split thickness grafting.

\section{DISCUSSION}

In the literature shrapnel has been reported as causing significant morbidity long after its insertion. ${ }^{2}$ In this case, had the patient been operated on sooner his wound may well have been grafted over leaving behind the dirty metal fragments. This may well have lead to abscess formation adjacent to the median nerve with significant consequences.

This case serves as a reminder that thorough secondary and tertiary surveys with relevant investigations are necessary in all trauma cases, ${ }^{3}$ especially when other distracting factors are present.

\section{Authors' affiliations}

J McKenzie, E Tiernan, Odstock Centre for Burns, Plastic and Maxillo Facial Surgery, Salisbury District Hospital, Salisbury, UK

Funding: none.

Conflicts of interest: none declared. 
Correspondence to: Mr J McKenzie, Department of Orthopaedic Surgery, Great Western Hospital, Marlborough Road, Swindon SN3 6BB, UK; watatu@btinternet.com

Accepted for publication 23 May 2003

\section{REFERENCES}

1 Deane S, Gunning K, Hodgetts T, eds. Trauma rules. London: BMJ Books, 1997.

2 Liew YM, Chia J, Low YP. Ann Acad Med Singapore 1995;24:867-8.

3 Driscoll P, Skinner D, eds. ABC of major trauma, 3rd edn. London: BMJ Books, 1999.

\section{Priapism as the presenting symptom of an aortocaval fistula} S Gordon, P Marsh, A Day, B Chappell

Emerg Med J 2004;21:265. doi: 10.1136/emj.2003.007302

The case of an elderly man with priapism as his only symptom is presented. The importance of clinical signs and simple investigations to make a diagnosis of aortocaval fistula associated with abdominal aortic aneurysm are discussed.

A n 83 year old man was referred to the urology team as an emergency with a prolonged, non-painful erection of about 12 hours duration. On examination an engorged, non-tender penis including the glans was discovered. Corporal cavernosal aspiration was undertaken and blood gas analysis was performed. These results were consistent with normal systemic venous blood. On further inquiry it was discovered that an abdominal aortic aneurysm had been diagnosed some years ago after a laparotomy for a self inflicted knife injury to the abdomen during an episode of severe depression. Abdominal examination revealed a large pulsatile mass consistent with an abdominal aortic aneurysm. Distal pulses were present and there was general venous engorgement of the superficial veins. Cardiovascular function remained stable and a urinary catheter was passed that revealed frank haematuria. Renal function was impaired with a rise in serum creatinine activity. A CT scan was performed to ascertain whether there was rupture of the aneurysm. This revealed a $14 \mathrm{~cm}$ aneurysm, which had not ruptured, but instead an aortocaval fistula existed. At this stage after discussion with the patient it was decided to perform an emergency operation to close the fistula and repair the aneurysm.

\section{DISCUSSION}

The associations between arterial aneurysms and priapism have been previously reported and include aortocaval fistulas ${ }^{1}$ and traumatic A-V malformations and aneurysms. ${ }^{2}$ There have also been cases of priapism after rupture of intracranial aneurysms. $^{3}$

Priapism is a rare condition particularly in this age group. In addition the presence of an erect corpus spongiosum as demonstrated by engorgement of the glans is also rare.
Incidence in the older age group is particularly attributable to treatments for erectile dysfunction. However the incidence of priapism is much lower with oral drugs when compared with intracorporeal agents. Blood gas analysis from the penis permits differentiation from the common form, so called veno-occlusive or low flow priapism, in which the oxygen content would be far lower than normal and lead to ischaemic changes.

The development of priapism in this man was therefore suspicious as he had not had an erection for many years and was not receiving any treatment for this condition. It is important as there are several factors that taken together allow a high index of suspicion to exist to make a diagnosis of aortocaval fistula. These include the presence of a known aneurysm, which had not been electively repaired and thus allowed to reach a large size. The corpus spongiosum was involved in the priapism and blood gas analysis revealed nonischaemic blood in addition to the prolonged erection with no associated pain thus indicating high flow priapism. The final important sign is that of frank haematuria attributable to venous engorgement that was also indicated by distended leg veins when lying down. An early emergency vascular opinion is necessary to ensure appropriate treatment is provided if these signs exist.

\section{Authors' affiliations \\ S Gordon, P Marsh, A Day, B Chappell, Department of Urology, Royal Sussex County Hospital, Brighton, UK \\ Correspondence to: Mr S Gordon, Sussex House, 1 Abbey Road, Brighton, BN2 1ES, UK; steveg543@hotmail.com}

Accepted for publication 6 May 2003

\section{REFERENCES}

1 Magee HR, Mellick SA. Aortocaval fistula as a complication of leaking aortic aneurysm. Br J Surg 1977;64:239-41.

2 Miller SF, Chait PG, Burrows PE, et al. Posttraumatic arterial priapism in children: management with embolization. Radiology 1995;196:59-62.

3 Takaku A, Fukawa O, Suzuki J. A case of priapism with ruptured intracranial aneurysm. J Neurol 1979;221:279-83. 